\title{
Optical Engines as Representative Tools in the Development of New Combustion Engine Concepts
}

\author{
J. Kashdan and B.Thirouard \\ IFP Energies nouvelles, Département Analyse Système Moteur, Division Techniques d'Applications Énergétiques, \\ 1-4 avenue de Bois-Préau, 92852 Rueil-Malmaison Cedex - France \\ e-mail: julian.kashdan@ifpen.fr - benoist.thirouard@ifpen.fr
}

Résumé - Moteurs transparents comme outils représentatifs dans le développement de nouveaux concepts des moteurs à combustion interne - Les moteurs monocylindres transparents sont employés comme outils de recherche et de développement des moteurs à combustion interne. Ils permettent l'utilisation de techniques de diagnostics non-intrusifs (qualitatifs et quantitatifs) pour étudier des phénomènes comme l'aérodynamique interne, la préparation du mélange, la combustion et la formation de polluants. Ces données expérimentales sont importantes pour la validation des modèles numériques et permettent également d'obtenir une compréhension détaillée des phénomènes physiques se déroulant dans la chambre. Les données recueillies aident au développement des nouvelles stratégies de combustion telles que la combustion homogène (HCCI) et la combustion Diesel à basse température (LTC). Dans ce contexte, il est important de s'assurer que le fonctionnement des moteurs transparents est tout à fait comparable et représentatif de celui des moteurs standards (opaques). Une comparaison du comportement de la combustion et des émissions des moteurs transparents et opaques a été réalisée. L'objectif était d'étudier les différences principales entre le moteur transparent et le moteur opaque et de comprendre comment ces différences peuvent influencer les phases de préparation du mélange, la combustion et la formation de polluants. Les résultats expérimentaux révèlent l'influence significative des différences liées à la température des parois de la chambre de combustion. Des mesures de la température des parois ont été effectuées par la technique de phosphorescence induite par laser. Ces mesures ont permis de définir des stratégies de fonctionnement moteur permettant de compenser les différences de température de paroi entre les deux moteurs. En outre, l'impact des différences géométriques des chambres a été investiguée. La réhausse piston peut subir soit un chargement mécanique dynamique (effets de compression ou de traction) soit une expansion thermique. Ces effets peuvent faire varier le taux de compression effectif. La charge admise dans les moteurs transparents est souvent diluée par de l'EGR simulé au lieu d'utiliser l'EGR réel. Dans les conditions de Diesel LTC, une comparaison a été effectuée entre l'utilisation d'EGR réel et d'EGR simulé par un gaz diluant pur. Enfin, les carburants mono-composants (carburants purs) sont souvent utilisés dans les moteurs Diesel transparents en raison des contraintes imposées par l'utilisation de techniques de diagnostics optiques. Cependant, les carburants purs diffèrent quelque peu des carburants Diesel réels, en particulier au travers de leur indice de cétane et de leur volatilité. Ces différences peuvent influencer fortement le comportement de la combustion et des émissions dans les moteurs transparents. Ces aspects ont été également traités dans cette étude.

Une meilleure compréhension des différences de comportement entre les moteurs monocylindres transparents et moteurs standards (opaques) a permis de développer des stratégies de fonctionnement permettant de compenser ces différences entre les deux moteurs. Il a été démontré dans cette étude qu'un 
recoupement du calage de la combustion et des émissions polluantes est possible même dans les conditions correspondant à la combustion Diesel LTC. La capacité d'assurer un comportement représentatif des moteurs transparents en termes de combustion et d'émissions augmente la valeur ajoutée des données expérimentales acquises soulignant alors l'importance de ces moyens comme outils de recherche dans le développement de nouveaux concepts de combustion.

\begin{abstract}
Optical Engines as Representative Tools in the Development of New Combustion Engine Concepts - Single cylinder optical engines are used for Internal Combustion (IC) engine research as they allow for the application of qualitative and quantitative non-intrusive, diagnostic techniques to study in-cylinder flow, mixing, combustion and emissions phenomena. Such experimental data is not only important for the validation of computational models but can also provide a detailed insight into the physical processes occurring in-cylinder which is useful for the further development of new combustion strategies such as gasoline Homogeneous Charge Compression Ignition (HCCI) and Diesel Low Temperature Combustion (LTC). In this context, it is therefore important to ensure that the performance of optical engines is comparable to standard all-metal engines. A comparison of optical and all-metal engine combustion and emissions performance was performed within the present study. The objective was to investigate the principal differences between optical and all-metal engines and understand how these differences ultimately affect mixing, combustion and emissions formation processes. Experimental results reveal the significant impact of differences in combustion chamber wall temperatures between optical and standard engine piston bowls on combustion phasing and engine-out emissions. Quantitative measurements of piston wall temperatures using a laser-induced phosphorescence technique were performed which allowed the subsequent definition of appropriate engine operating strategies so as to compensate for differences in heat transfer properties. Furthermore, differences in combustion chamber geometry were also studied. Geometrical differences can arise as a result of dynamic (compressiveltensile) and thermal loading of the extended piston-liner assembly on the optical engine, potentially leading to changes in the effective Compression Ratio. In addition, intake charge dilution in optical engines is often achieved via the use of simulated Exhaust Gas Recirculation (EGR). A comparison has been made between simulated EGR (using pure nitrogen) with real EGR under Diesel LTC conditions. Finally, "pure", single component fuels are often employed in optical Diesel engines due to laser diagnostic constraints. However, these fuels generally differ from standard Diesel fuel in terms of cetane number and fuel volatility which can significantly influence the combustion and emissions characteristics in optical engines. These aspects have also been investigated within the present study.

An improved understanding of the differences between optical and all-metal engines has allowed us to develop appropriate strategies to compensate for these differences on the optical engine. It is shown here that combustion phasing (and engine-out emissions) matching between optical and all-metal engines can be achieved even for advanced LTC Diesel combustion strategies. The ability to ensure fully representative combustion and emissions behaviour of optical engines ultimately increases the value of optical engine data, highlighting the importance of using such engines as research tools for the further development of innovative, low emission combustion concepts.
\end{abstract}

\section{DEFINITIONS}

$\begin{array}{ll}\text { BDC } & \text { Bottom Dead Center } \\ \text { CA } & \text { Crank Angle } \\ \text { CFR } & \text { Cooperative Fuel Research } \\ \text { CN } & \text { Cetane Number } \\ \text { CO } & \text { Carbon Monoxide } \\ \text { CR } & \text { Compression Ratio } \\ \text { DI } & \text { Direct Injection } \\ \text { EGR } & \text { Exhaust Gas Recycle } \\ \text { FT } & \text { Fischer Tropsch } \\ \text { HC } & \text { Hydrocarbons }\end{array}$

HCCI Homogeneous Charge Compression Ignition

IMEP Indicated Mean Effective Pressure

LIF Laser-Induced Fluorescence

LIP Laser-Induced Phosphorescence

LTC Low Temperature Combustion

$\mathrm{NO}_{x} \quad$ Nitrogen Oxides

RPM Revolutions per Minute

SI Spark Ignition

SOI Start of Injection

$T_{b} \quad$ Boiling Point

TDC Top Dead Center 


\section{INTRODUCTION}

Advances in Internal Combustion (IC) engine performance, notably in terms of improved fuel economy and reduced engine-out emissions, have been largely a result of significant combined research and development efforts by automotive companies, suppliers, research institutes and universities. Over the last two decades in particular, the development and application of both experimental and computational research and development tools has enabled for a more in-depth understanding of fundamental physical phenomena occurring in IC engines. With regards to experimental engine research, single-cylinder, optical-access engines have been widely used as they allow the application of both qualitative and quantitative, non-intrusive, optical diagnostic techniques to gain a detailed insight of the mixing, combustion and emissions formation processes occurring in-cylinder. Although earlier work performed on optical engines provided useful experimental data enabling an improved understanding of fundamental in-cylinder physical phenomena and for the validation of CFD models, the value of optical engine data was often deemed to be rather limited from the engine developer's point of view since optical engines were not considered to be fully representative of standard "all-metal" engines. In particular, certain compromises are often made

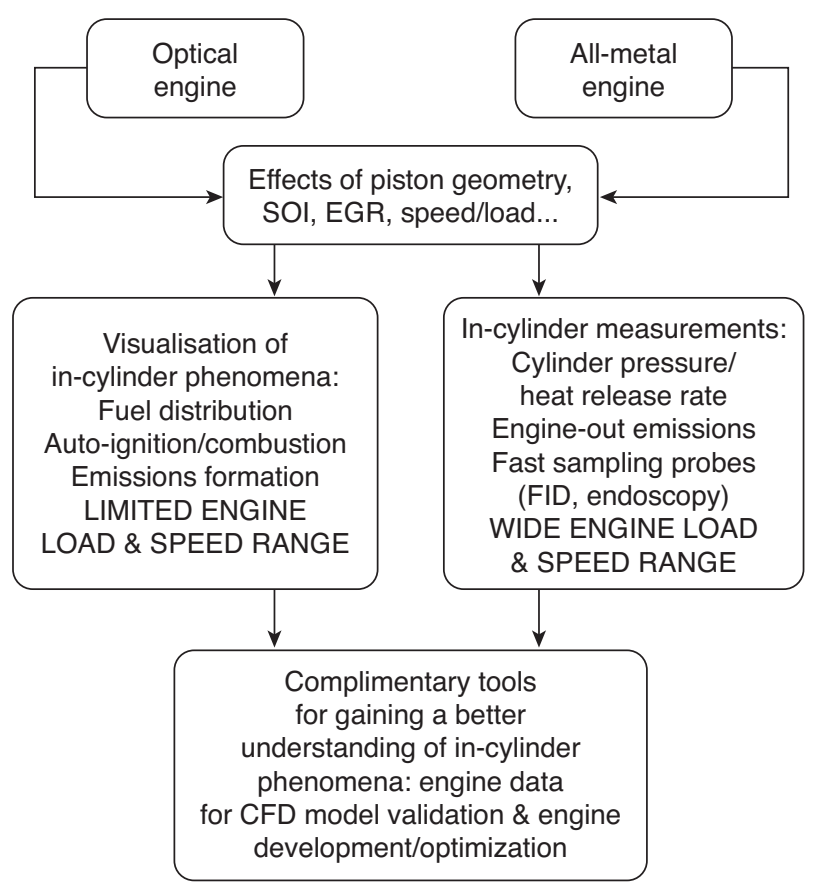

Figure 1

Schematic flowchart illustrating a combined optical/all-metal engine experimental study and the complimentary data that can be acquired. such as the use of simplified piston bowl geometries in order to maximise engine optical access. Furthermore, single-component fuels rather than standard commercial fuels are often employed due to laser diagnostic constraints. Non-standard piston rings manufactured from specialist materials are also used on optical engines due to the need to "dry-run" these engines (i.e. the upper cylinder liner on the optical engine is not lubricated) and as a result, it is often claimed that engine blow-by is more significant in optical engines compared to standard engines.

More recently, studies of in-cylinder combustion processes are tending to rely upon a combined approach whereby experiments are performed on both an optical and an identical, standard, all-metal engine $[8,18,19]$. There are clearly several advantages to such an approach. Firstly, experimental data can be obtained on all-metal engines at a much higher rate in order to establish an expansive database in which a multitude of engine parameters can be studied. As shown in Figure 1 for example, variations may include injection timing/strategies, coolant/intake temperature, level of charge dilution, equivalence ratio and intake pressure.

Experiments on all-metal engines therefore allow an exhaustive experimental database to be established relatively quickly. A subsequent analysis of these data may reveal interesting trends which can be investigated in more detail on the optical access engine. In particular, the application of appropriate laser-based diagnostic techniques on the optical access engine can provide results which can lead to an improved understanding of the physical phenomena occurring in-cylinder.

There have been surprisingly few studies dedicated to investigating the differences between optical and all-metal engines despite the widespread use of engine optical diagnostic techniques particularly in the last two decades. Work reported in Reference [1] focused on characterizing the piston surface temperatures on optical and all-metal engines via cycle-resolved thermocouple measurements in a Direct Injection Spark Ignition (DISI) engine. The experimental results revealed that surface temperatures on the optical piston significantly exceeded the so-called reference temperature of $\sim 150^{\circ} \mathrm{C}$ corresponding to the all-metal engine. The data was then used to determine an optimum skip-firing routine (10 fired cycles followed by 100 motored cycles) so that optical measurements could then subsequently be performed at piston surface temperatures considered to be representative of the all-metal engine.

More recent studies [6,7] have been performed on highlighting the need to characterise the differences between optical and all-metal engines. Colban et al. [5] performed a detailed study into the effects of EGR composition and in particular the use of simulated EGR on optical engines and the importance of including the major species such as $\mathrm{N}_{2}, \mathrm{CO}_{2}$, $\mathrm{H}_{2} \mathrm{O}, \mathrm{CO}$ and UHC. In-cylinder pressure matching under motored conditions between the optical and all-metal engines 
was also discussed. The TDC thermodynamic conditions on the optical engine were matched to those of the all-metal engine by adjusting the intake mass flow and composition, intake temperature and fueling rate. Aronsson et al. [7] studied several optical engine configurations and compared experimental data with results obtained on a standard allmetal engine. The authors reported the effects of the material properties of optical components (windows) on the combustion process. The use of low conductivity materials such as quartz was found to have a significant impact on the heat release rate characteristics.

Other aspects must also be considered. For example, the use of realistic optical engine combustion chamber geometries, identical to the geometries of their metal engine counterparts is also a major issue. Whenever possible, it is important to maintain a fully representative combustion chamber design since this plays a significant role on mixture preparation (in-cylinder airflow, fuel-air mixing, fuel-wall impingement), combustion and emissions. For optical-access Diesel engines, the application of diagnostic techniques is further complicated by the fact that the combustion process is confined within the piston bowl. The use of realistic chamber geometries therefore implies piston windows which incorporate piston crown shapes. Many optical engines used for in-cylinder visualisation studies have been based on simplified chamber geometries so as to facilitate optical access whilst minimising image distortion issues. A number of studies have however been performed with fully representative piston bowl geometries [1-5]. In Reference [2], optical ray-tracing algorithms were employed so that the in-cylinder images could be postprocessed in such a way as to "correct" for image distortion due to curved window surfaces.

The objectives of the current study are not only to identify the principal differences between an optical engine and an equivalent all-metal engine but to understand the effects of these differences on optical engine performance (combustion and emissions characteristics). Furthermore, it is shown here that gaining a better insight into optical engine behaviour is useful in helping to identify a means by which experiments on optical engines can be performed under conditions which are fully representative of all-metal engines. Examples of such approaches are provided later in the paper. The need for a better understanding of optical engine characteristics and their comparison with standard all-metal engines is particularly important if optical engines are to be used in parallel with all-metal engines in order to gain a better understanding of engine combustion phenomena.

\section{DIFFERENCES BETWEEN OPTICAL AND METAL ENGINES}

There are numerous fundamental differences between optical-access and all-metal engines which are discussed below. The 3D schematic shown in Figure 2 presents the main components of the IFPEN Diesel optical engine including the extended piston assembly, optical-access piston and grooves showing the piston ring and guide locations.

\subsection{Materials and Heat Transfer Considerations}

Optical-access engines, as their name implies rely on the replacement of a number of metal engine parts by "transparent" windows, allowing visual access into the combustion chamber. The windows are typically made from quartz (fused silica) and/or sapphire. The single-cylinder, optical Diesel engine at IFPEN incorporates quartz piston windows in the base of the piston bowl and smaller windows housed within sections of the reentrant piston wall (Fig. 3). A fully transparent sapphire ring is also used which is sandwiched between the cylinder liner and the cylinder head. The selection criteria for the choice of window materials is not only based on mechanical property considerations but also on

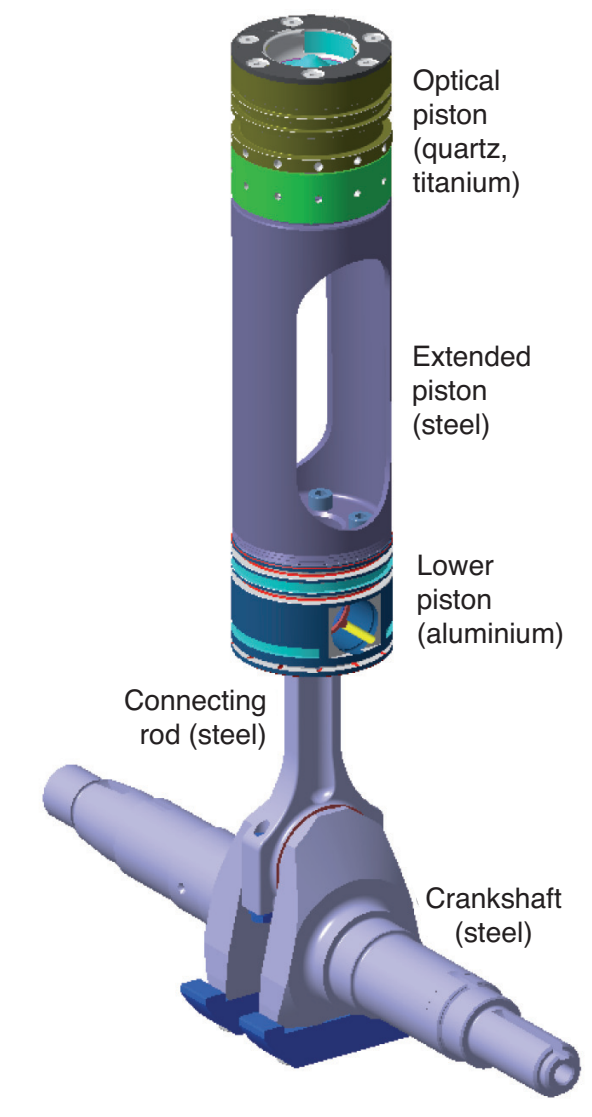

Figure 2

3D schematic showing main components of the optical engine including the extended piston assembly and optical piston. 


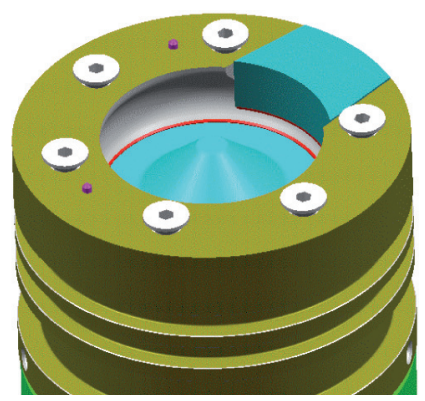

Figure 3

Optical-access Diesel piston bowl showing location of quartz windows.

their optical properties [6]. Furthermore, the optical-access piston head used in the current study which houses the windows is made from titanium due to its high strength-toweight ratio. The extended piston used in this study was manufactured from steel which in this case offered the best strength-to-weight ratio.

As will be discussed, the use of materials such as quartz, sapphire and titanium in optical engines has a significant impact on engine combustion characteristics thus bringing into question the fidelity of optical engine performance compared with an identical all-metal engine. The reason for this is that the thermal conductivity of the aforementioned materials is significantly lower than the thermal conductivity of aluminium (aluminium being the base material used for the manufacture of all-metal pistons). Table 1 compares values of thermal conductivity of typical materials used in combustion chambers of optical and all-metal engines. The three principal materials used in the IFPEN optical engine (titanium, quartz and sapphire) are all characterized by thermal conductivities which are significantly lower than that of aluminium. The differences in thermal conductivity between an optical-access piston and an all-metal piston will inevitably lead to considerable differences in engine heat transfer characteristics. Higher piston surface temperatures would subse-

\section{TABLE 1}

Comparison of values of thermal conductivity of common materials used in combustion chambers of optical and all-metal research engines

\begin{tabular}{c|c}
\hline Material & $\begin{array}{c}\text { Thermal conductivity } \\
\left(\mathrm{Wm}^{-1} \mathrm{~K}^{-1}\right) \text { at } 20^{\circ} \mathrm{C}\end{array}$ \\
\hline Aluminium/Silicon (A188/Si12) & 121 \\
\hline Cast Iron & $27-46$ \\
\hline Titanium & 22 \\
\hline Sapphire & $35-40$ \\
\hline Quartz & 1.5 \\
\hline
\end{tabular}

quently be expected on optical engines which would then be expected to lead to notably higher bulk gas temperatures, thus having a major effect on the combustion characteristics. Furthermore, the high combustion chamber surface temperatures could potentially compromise the mechanical strength of the optical components. In particular, high temperature gradients across the windows might subsequently lead to excessive thermal-induced stresses and mechanical failure. Measurements have been performed within the current study in order to quantify the differences in piston wall surface temperature between optical and all-metal engines.

\subsection{Geometry and Engine Architectural Considerations}

As mentioned above, the use of optical engines often imposes simplifications to the combustion chamber geometry in order to facilitate the application of laser-diagnostic techniques. Differences in combustion chamber geometry between optical and all-metal engines can have a significant impact on the mixture preparation, combustion and emissions characteristics [6]. Furthermore, the location of the piston ring pack on optical engine combustion chambers might differ from that of the all-metal engine. On optical engines, the use of two-part optical-access cylinder liners (e.g. sapphire or quartz rings) requires that the upper piston rings are lowered (compared with a standard all-metal piston) so as to avoid overlap (and subsequent sealing problems) of the piston rings at the interface between the metal liner and the transparent ring. This difference inevitably leads to an increased piston top land crevice volume [8] which will reduce the engine Compression Ratio (CR). Other geometrical parameters such as the squish height and the injector nozzle tip protrusion should also be similar between both engines so as not to adversely affect the in-cylinder airflow/turbulence and jet-wall impingement location respectively.

Geometrical differences may also arise as a result of static and dynamic effects. Changes in the geometry of the extended piston assembly might occur due to excessive thermal loading. For example, the low conductivity of materials such as quartz, sapphire and titanium will give rise to higher temperatures which could lead to significant thermal expansion. Thermal expansion of the extended piston assembly will tend to reduce the squish height and thereby increase the Compression Ratio. Indeed, these effects were studied in Reference [6] where it was reported that an expansion of $0.4 \mathrm{~mm}$ led to an increase of the CR of approximately 1.2. Dynamic effects due to compression of the extended piston assembly may also induce changes in the combustion chamber volume and therefore the effective Compression Ratio. Colban et al. [6] attempted to characterize such behaviour using a hydraulic press to simulate such dynamic loading effects. Their measurements revealed that the overall length of the extended piston assembly reduced by approximately 
$0.23 \mathrm{~mm}$ when subjected to a static pressure of $85 \mathrm{bar}$ corresponding to a decrease of the CR of 0.6. However, it should be noted that the experimental results reported in Reference [5] did not account for inertial effects. Design calculations have been performed within the present study in order to estimate the compliance of the extended piston. The calculations performed here take into account the effects of the cylinder pressure which might result in compression of the extended piston. Furthermore, the inertial effects of the moving piston assembly are accounted for. The data was then exploited in order to evaluate whether differences of the measured in-cylinder pressures between the optical and all-metal engines (and therefore the effective Compression Ratio) were due mainly to the dynamic loading effects and/or the effects of engine blow-by.

Other considerations which might appear trivial but require particular attention when attempting to replicate a series of experiments on two separate engines concern the locations of instruments such as the pressure transducer, thermocouple and exhaust gas sampling line. The measurement location of parameters such as intake or exhaust gas temperature and pressure, $\mathrm{CO}_{2}$ exhaust and intake gas sampling location for EGR measurements will have a significant influence on the measured values. It is therefore important that the measurements are performed at identical locations on both the all-metal and optical engines. These issues have been addressed for the experiments described in the current study on the all-metal and optical engines.

\subsection{EGR Composition}

The composition of Exhaust Gas Recycle (EGR) is another potential source of differences between optical and all-metal engines since simulated EGR is often employed on optical engines. This is due to the fact that optical engines are often operated using skip-firing strategies which means that the engine-out exhaust gases from the previous motored cycle(s) will significantly dilute any EGR gases which might be recycled with the intake air. Optical engine experiments can of course be performed without skip-firing so as to operate using real EGR gases. However, this approach will clearly exacerbate the issues related to the engine wall heat transfer characteristics. As explained above and as will be shown later in the paper, the combustion chamber surface temperatures are significantly higher in optical engines due to the low thermal conductivity of optical windows (quartz and sapphire). This leads to reduced heat flux resulting in higher combustion chamber surface and bulk gas temperatures. The higher combustion temperatures will have a significant effect on the fuel oxidation reactions and the subsequent formation of various pollutants such as $\mathrm{NO}_{x}, \mathrm{HC}$ and $\mathrm{CO}$. As a result, the EGR gas composition on the optical engine will be modified compared to a standard all-metal engine under similar engine operating conditions.

\subsection{Blow-By}

Differences in performance between optical and all-metal engines are often attributed to the effects of increased engine blow-by on optical engines. Although this parameter is measurable on standard, all-metal engines using flow meters, it is not straightforward to perform direct measurements of engine blow-by on standard optical engines. The difficulties of measuring blow-by on optical engines are due to the use of elongated pistons ad the fact that the crankcase is not closed as on standard engines. Specific modifications to the optical engine would thus have to be made in order to perform blow-by measurements.

\subsection{Fuel Considerations}

As mentioned above, single component or "pure" fuels are often used for experiments performed on optical engines. Such fuels are employed for two main reasons. Firstly, it is necessary to use single component fuels due to laser diagnostic constraints and in particular to avoid the fluorescence of various molecular species (e.g. naphthenic and aromatic compounds) which are naturally present in standard or commercially available Diesel and gasoline fuels. Secondly, the requirement to use such fuels is also driven by the limited capability to model the combustion of more complex, multicomponent fuels.

Isooctane (or mixtures of isooctane and $n$-heptane) is a single component fuel widely employed as a surrogate fuel since it is considered representative of standard gasoline since they have similar Boiling Points while lower volatility pure fuels such as decane and dodecane are often employed in Diesel engine studies. However, in this latter case, the fuel Cetane Numbers of decane ( $\mathrm{CN} \sim 76)$ and dodecane $(\mathrm{CN} \sim 71)$ are significantly higher compared with both standard Euro V $(\mathrm{CN} \sim 52)$ and US $(\mathrm{CN} 42)$ Diesel fuels. Clearly, the use of higher Cetane Number pure fuels will have a major impact on the auto-ignition delay and under Diesel LTC operating conditions may also influence the low temperature (coolflame) oxidation reactions. If non-fluorescing fuels must be used on optical engines, it is important to ensure that the fuel ignition characteristics are considered if the objective is to use the optical engine as a complimentary tool to study phenomena occurring on all-metal engines, the latter being operated using standard commercial fuels. These aspects have been investigated in the present study and are discussed later in the paper.

\section{EXPERIMENTAL}

The optical-access and all-metal engines used in this study were both single-cylinder and correspond to light duty Direct Injection (DI) Diesel engines. The general engine characteristics are presented in Table 2. Both engines were equipped 
with common rail fuel injection systems (Bosch CP2) capable of supplying fuel at nominal rail pressures up to 1600 bar. A six-hole injector nozzle with a $60^{\circ}$ included angle was used for the majority of the experiments described in this paper. In-cylinder pressure measurements were acquired using a water-cooled piezoelectric pressure transducer (Kistler 6043A60). Pressure data was obtained over 200 engine cycles while a $0-\mathrm{D}$ combustion analysis was performed in order to obtain parameters such as heat release rate and burned mass fraction. An optical Crank Angle encoder providing 0.1 CAD resolution was used. Both engines were equipped with an intake heater allowing pre-heating of the fresh intake air (or in the case of the optical access engine, the air-nitrogen mixture for operation under simulated EGR conditions). Both engines were equipped with identical EGR circuits while the location of various measurement instrumentation such as pressure transducers, thermocouples and exhaust gas sampling lines were identical on both the optical and all-metal engines.

TABLE 2

Engine specifications of the all-metal and optical-access engines used in this study

\begin{tabular}{l|c|c}
\hline & All-metal engine & Optical engine \\
\hline Engine base type & 2 litre, DI Diesel & 2 litre, DI Diesel \\
\hline Number of cylinders & 1 & 1 \\
\hline Number of valves & 2 int. $+2 \mathrm{ex}$. & 2 int. $+2 \mathrm{ex}$. \\
\hline Bore/stroke & $85 / 88 \mathrm{~mm}$ & $85 / 88 \mathrm{~mm}$ \\
\hline Displacement & $0.5 \mathrm{~L}$ & $0.5 \mathrm{~L}$ \\
\hline Squish height & $0.80 \mathrm{~mm}$ & $0.80 \mathrm{~mm}$ \\
\hline Compression Ratio & 14 & 14 \\
\hline Swirl ratio & 1.1 & 1.1 \\
\hline
\end{tabular}

\subsection{Combustion Chamber Geometry}

In order to compare optical and all-metal engine data, a fully representative combustion chamber geometry was used on the optical-access engine. The optical piston geometry was essentially identical to that of the all-metal engine as shown in Figure 4.

The minor differences that can be observed are the piston bowl floor between the bowl-dome and the re-entrant wall. In order to facilitate the application of optical diagnostic techniques, it was desirable to maintain a flat surface for the bowl floor. For example, laser sheet illumination of the combustion chamber would be complicated if the laser sheet was passed through curved surfaces due to window lensing effects. Minor differences can also be observed in terms of the re-entrant curvature near the base of the piston. The

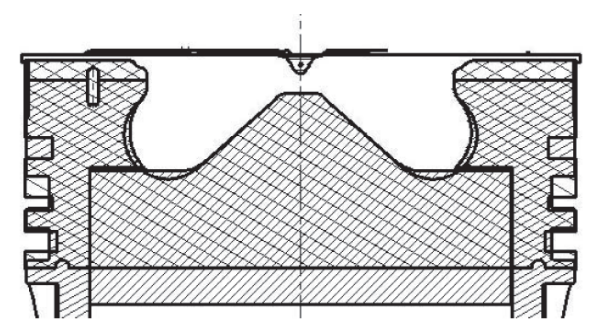

Figure 4

Comparison of optical-access and all-metal engine combustion chamber geometries.

optical piston has a slightly larger radius of curvature which compensates for the shallower bowl depth (due to the flat bowl floor). Furthermore, the slightly greater piston topland crevice volume on the optical engine (due to the lowered piston ring pack) is also compensated for. This ensures that the combustion chamber volume is identical for the optical and the standard, metal engine thus ensuring identical geometric Compression Ratios for the two engines.

\subsection{Laser-Induced Phosphorescence Thermography}

Piston wall-surface temperature measurements were performed within the present study via the technique Laser-Induced Phosphorescence (LIP) described in more detail in [9]. This technique exploits the temperature-dependent light emission (phosphorescence) characteristics of rare-earth-doped ceramic phosphors. An extensive review of the phosphorescence technique is provided in Reference [10] while several publications are available which report on various applications of the technique in a range of environments including IC engines [10-13] and gas turbines [14,15]. The principal advantages of the phosphorescence technique are that it provides non-intrusive and emissivity-independent wall temperature measurements. Phosphorescent emission is excited following exposure to visible or ultraviolet (UV) light. The spectral, intensity and lifetime characteristics of the phosphorescence signal depend on temperature.

Temperature measurements were performed within the current study with the objective of quantifying the piston surface temperatures of the optical and all-metal combustion chambers. The experimental data could then be compared with the combustion and emissions data for the two engine configurations allowing a more detailed understanding of the effects of differences in the material/thermal properties on the engine combustion characteristics. Furthermore, quantitative surface temperature data could be exploited so as to identify/establish operating conditions for the optical engine which would correspond to all-metal engine conditions. 


\section{Phosphorescence Lifetime Measurements}

The criteria for the choice of phosphor is based on the temperature range that can be measured with the phosphor. In the present study, measurements of piston surface temperature were envisaged. Typically, piston surface temperatures are expected to be in the range 150 to $300^{\circ} \mathrm{C}[1,16]$. The selected phosphor used in this study was lanthanum oxysulphide $\left(\mathrm{La}_{2} \mathrm{O}_{2} \mathrm{~S}: \mathrm{Eu}\right)$. The mean particle size distribution (data obtained from supplier) was approximately $5 \mu \mathrm{m}$. Singlepoint temperature measurements were performed in the present study which were based on estimating the lifetime of the phosphorescence signal. Phosphorescence was excited by using a frequency-tripled Nd:YAG laser at $355 \mathrm{~nm}$. The measurement principle is shown schematically in Figure 5. A thin $(<100 \mu \mathrm{m})$ phosphor layer is applied to the target surface (e.g. piston surface). Following laser excitation, the emitted phosphorescence signal is detected by a photomultiplier and appropriate collection filters. The phosphorescence signal intensity decreases in an exponential manner. The lifetime of the phosphorescence emission is dependent on the surface temperature and can be approximated with Equation (1):

$$
I(t)=I_{0} \exp \left(\frac{-t}{\tau}\right)+B
$$

where $I_{0}$ is the peak intensity (upon laser excitation), $t$ is time, $\tau$ is the signal lifetime and $B$ is a constant corresponding to the measurement offset.

Piston surface temperatures were measured within the squish zone on one of the exhaust valve cut-outs as shown in Figure 6. One of the two exhaust ports was modified in order to provide optical access to the combustion chamber. A round sapphire window replaced one of the two exhaust valves and a mirror was positioned within the modified exhaust port as shown in Figure 7. A backscattering optical

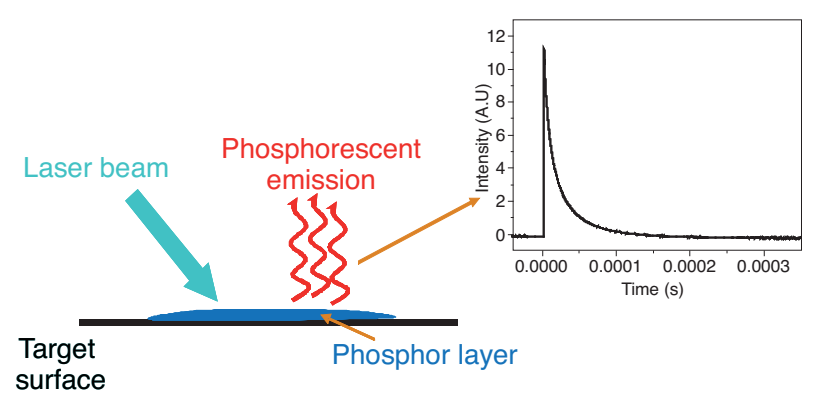

Figure 5

Measurement principle of Laser-Induced Phosphorescence for surface temperature measurements based on detection of phosphorescence lifetime. setup was used: i.e. the mirror allowed the laser beam to be accurately aligned within the combustion chamber and also served to retro-collect the diffuse phosphorescence signal which was detected by the photomultiplier. This configuration ensured that optical access was kept to the minimum necessary levels for the diagnostic technique. Ensemble-averaged LIP data was acquired such that 100 measurements from consecutive engine cycles were obtained at each Crank Angle position.

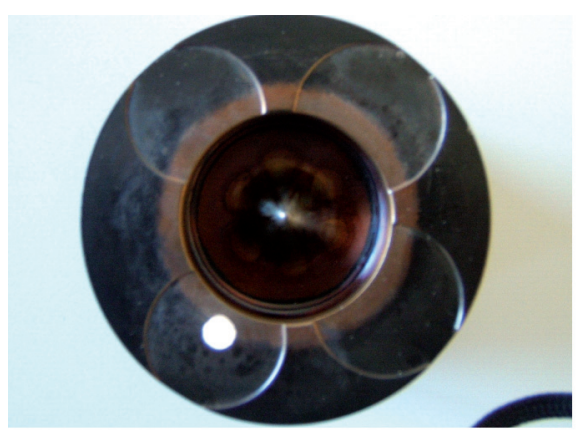

Figure 6

Photograph of Diesel piston showing location of surface temperature measurements performed via Laser-Induced Phosphorescence.

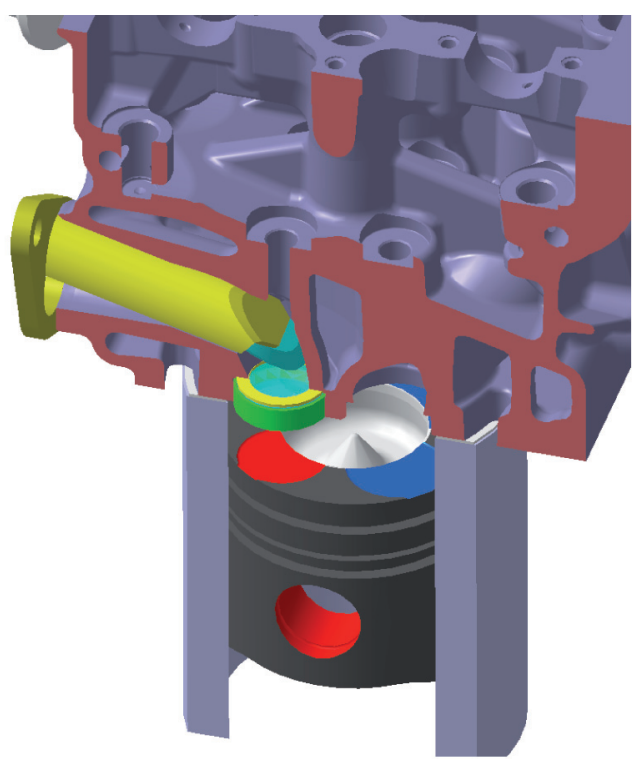

Figure 7

$3 \mathrm{D}$ view of engine combustion chamber showing optical access via one of the two exhaust ports enabling piston surface temperature measurements. 


\section{RESULTS}

\subsection{Material and Heat Transfer Effects}

A comparison of in-cylinder pressure traces under motored operation for the optical and all-metal engines is shown in Figure 8 . The intake air mass flow rate of the optical engine was matched to that of the all-metal engine. The cylinder pressure at Bottom Dead Centre (BDC) was verified to be identical between the two engines. The optical engine Compression Ratio was adjusted (by varying the squish clearance) in order to obtain identical peak cylinder pressures. Under these conditions, the estimated geometric Compression Ratio on the optical engine was 14.5:1 compared with 14.1 for the all-metal engine. Possible explanations for these differences are discussed later in the paper.

Having obtained comparable in-cylinder pressures under motored conditions, a comparison of fired pressure traces acquired on the all-metal and optical engines is shown in Figure 9. An engine operating condition of $1500 \mathrm{rpm}, 2$ bar IMEP without EGR. Note that the optical engine for this condition was operated without skip-firing. The data in Figure 9 clearly show that combustion phasing is significantly advanced in the case of the optical engine. Furthermore, the pressure rise rate is significantly higher. Adjusting the SOI timing in $1{ }^{\circ} \mathrm{CA}$ increments allows some degree of control over ignition timing however this is clearly not an ideal solution to achieve combustion phasing matching. Firstly, adjusting the SOI timing alters the fuel jet wall impingement location within the piston bowl which can influence mixture preparation, particularly in such wall-guided combustion chamber systems as discussed in Reference [4]. Secondly, Figure 9 reveals that despite adjusting the SOI timing, differences in pressure rise rates between the optical and metal engines are still observed.

The advanced combustion phasing and higher pressure rise rates observed on the optical engine are believed to be due to the higher bulk gas and combustion chamber wall temperatures which arise as a result of the much lower thermal conductivity of optical pistons.

A comparison of fired pressure traces is shown in Figure 10 obtained on the optical engine (equipped with an optical window in the base of the piston) and on the all-metal engine for a case with EGR. The engine settings used on the all-metal engine such as SOI timing, fuel injection pressure and duration and intake airflow rate and pressure were employed on the optical engine. It should be noted that EGR on the optical engine was simulated using pure nitrogen. The level of charge dilution using pure nitrogen was adjusted so as to obtain equivalent oxygen concentrations between the two engines. The schematic representation of Figure 11 shows the major constituent gases $\left(\mathrm{N}_{2}, \mathrm{O}_{2}, \mathrm{CO}_{2}, \mathrm{H}_{2} \mathrm{O}\right.$ and any excess air) present in real EGR used on a standard all-metal engine. Clearly, depending upon the engine operating condition, some excess air may be present within the EGR gases. The corresponding proportion of this excess air $\left(\mathrm{N}_{2} / \mathrm{O}_{2}\right)$ was taken into account in the present study in which EGR on the optical engine was simulated via pure nitrogen.

As shown in Figure 10, significant differences in combustion phasing can be observed between the two engines. Combustion phasing is significantly advanced in the case of the optical engine with auto-ignition occurring several Crank

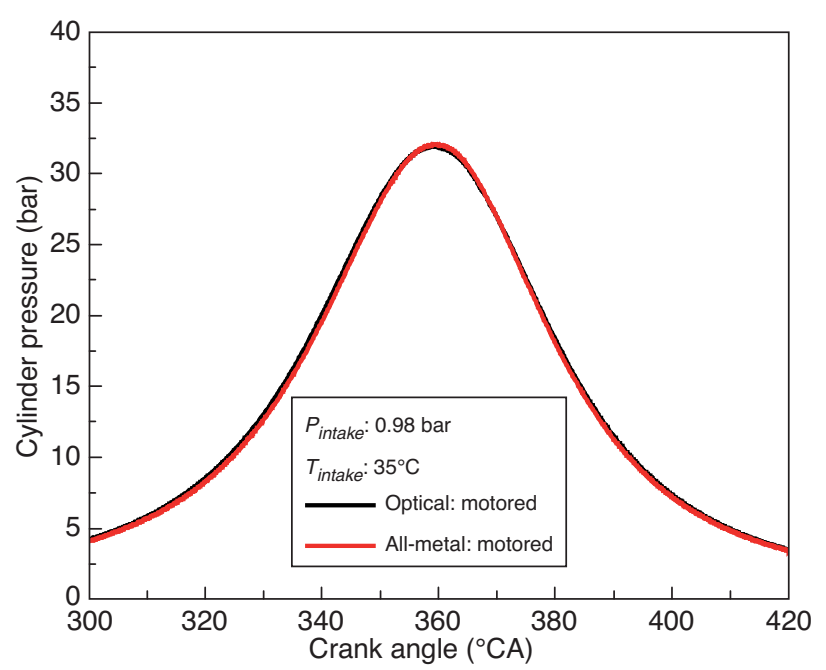

Figure 8

Comparison of motored pressure traces obtained on optical and all-metal engine.

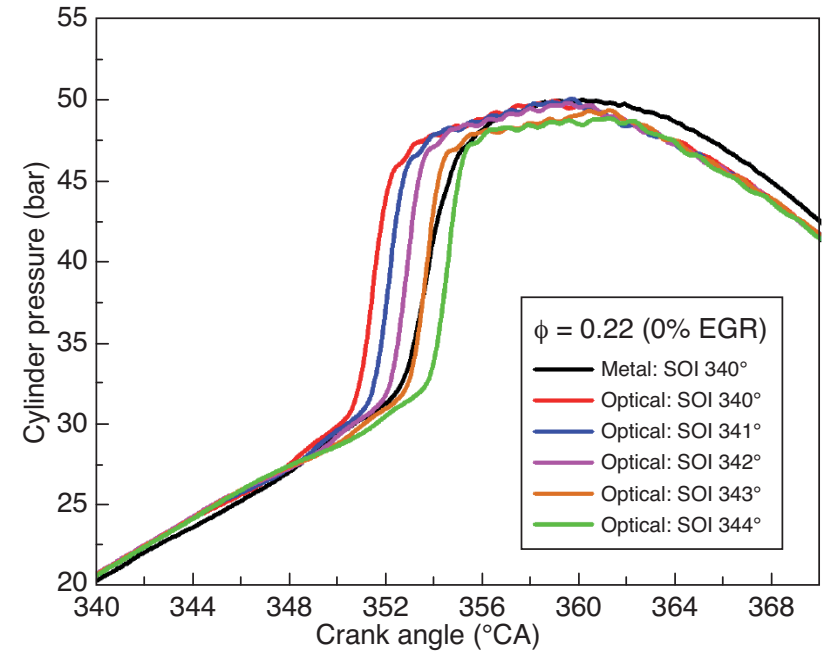

Figure 9

Comparison of fired pressure traces without EGR, $1500 \mathrm{rpm}$, 2 bar IMEP, $P_{i n j} 1000$ bar, standard Diesel fuel. 


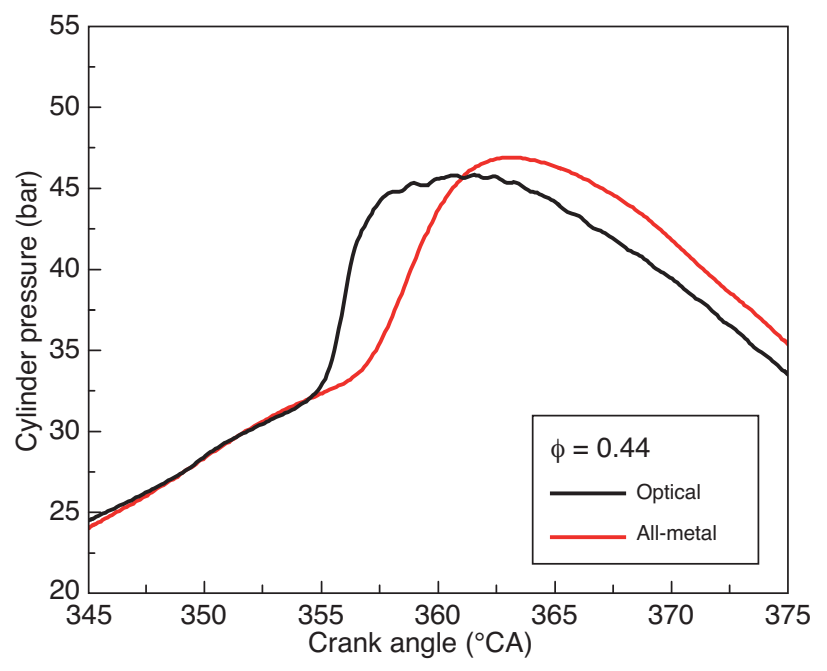

Figure 10

Comparison of fired pressure traces obtained on optical (without skip-firing) and all-metal engine, SOI $340^{\circ} \mathrm{CA}$, simulated EGR, $1500 \mathrm{rpm}, 2$ bar IMEP, $P_{i n j} 1000$ bar, standard Diesel fuel.

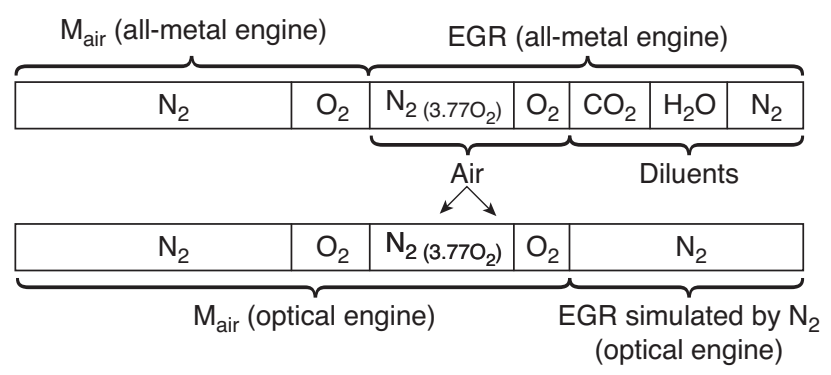

Figure 11

Schematic representation of intake charge on a standard allmetal engine (air/EGR) and on an optical engine using simulated EGR (air/ $\left.\mathrm{N}_{2}\right)$.

Angle degrees earlier compared with the all-metal engine. Clearly, the results show that simply adopting the engine settings used on the all-metal engine on the optical engine is not sufficient to reproduce similar combustion behaviour. Advanced combustion phasing was observed to be systematic over a very wide range of engine operating conditions on the optical engine and is clearly due to the higher wall temperatures as a result of the lower thermal conductivity of the optical engine piston head. The high wall temperatures on the optical engine lead to higher bulk gas temperatures leading to shorter auto-ignition delays and thus advanced combustion phasing. Since significant differences in combustion phasing are observed, it is inevitable that the level of engine-out emissions also differ significantly.

A comparison of engine-out hydrocarbon (HC) emissions measured on both the optical and all-metal engines is shown

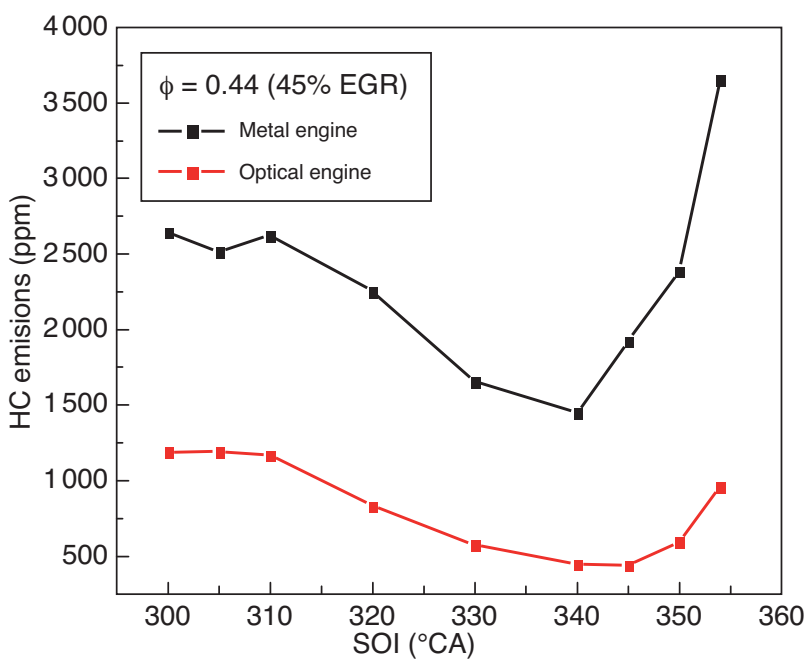

Figure 12

Comparison of measured engine-out $\mathrm{HC}$ emissions obtained on optical and all-metal engines for a SOI timing sweep, EGR 45\% (simulated EGR on optical engine), $1500 \mathrm{rpm}$, $\sim 2$ bar IMEP, $P_{i n j} 1000$ bar, standard Diesel fuel.

in Figure 12 for a SOI timing sweep in the range 300 to $355^{\circ} \mathrm{CA}$ under highly dilute Diesel LTC operating conditions (simulated EGR was used corresponding to a real EGR rate of $45 \%$ ).

Overall, the $\mathrm{HC}$ emissions are approximately two to three times lower on the optical engine compared with the all-metal engine. The differences in $\mathrm{HC}$ emissions can be explained by the differences observed in combustion phasing. The advanced combustion phasing due to shorter ignition delays observed on the optical engine is attributed to the higher in-cylinder temperatures encountered which are a direct consequence of the lower thermal conductivity in optical pistons compared to all-metal pistons. The higher bulk gas temperatures not only affect ignition timing but also the level of $\mathrm{HC}$ (and presumably $\mathrm{CO}$ ) emissions. As previously reported in Reference [8], bulk quenching has been shown to be a significant source of $\mathrm{HC}$ emissions, due to excessively low combustion temperatures leading to incomplete oxidation. Since HC formation as a result of bulk quenching is closely coupled to temperature, the significantly higher combustion temperatures which are achieved as a result of lower thermal conductivities in optical engine combustion chambers leads to a major reduction in $\mathrm{HC}$ emissions levels (Fig. 12).

In order to confirm whether the differences in combustion phasing observed between optical and all-metal engines are primarily due to differences in piston material thermal conductivity, a back-to-back comparison was performed on the optical engine using the optical-access piston with an allmetal piston bowl manufactured entirely from aluminium (the material typically used for the manufacture of production 


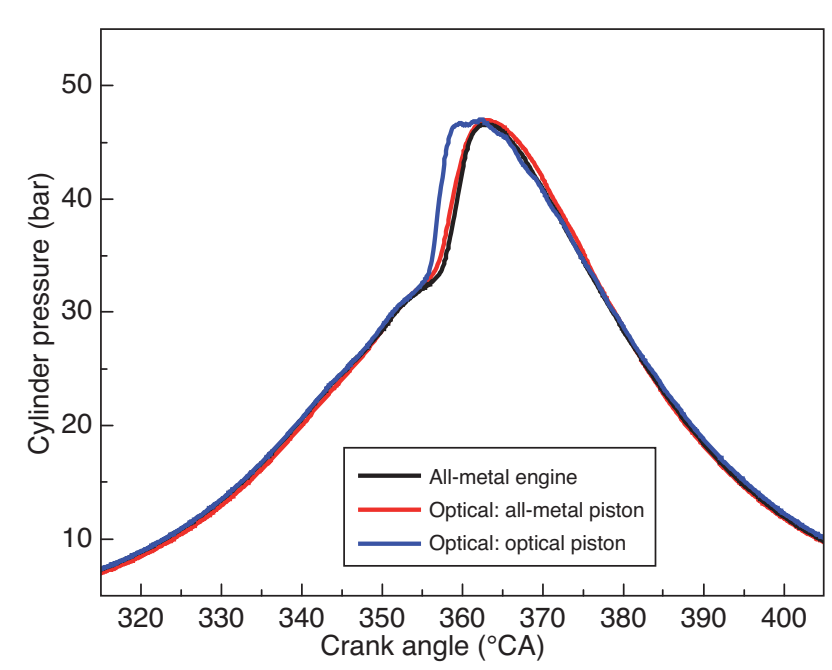

Figure 13

Comparison of fired pressure traces obtained on all-metal engine (black) and optical engine using optical-access (blue) and all-metal (red) piston heads (SOI $340^{\circ} \mathrm{CA}$, simulated EGR).

series pistons in standard engines). In-cylinder pressure traces (Fig. 13) corresponding to tests performed on the optical engine with (1) an optical-access piston assembly (made from quartz and titanium) and (2) an all-metal piston (made from aluminium) are compared with the pressure trace obtained on a standard, all-metal engine. It should be noted that the tests on the optical engine were performed without employing a skip-firing strategy. The results in Figure 13 reveal an excellent agreement in terms of the combustion phasing corresponding to the all-metal piston head used on the optical engine with that obtained on the standard allmetal engine. Meanwhile, one notes that the combustion phasing is clearly over-advanced in the case of the optical piston. These data therefore confirm that the piston material properties, and in particular, the material thermal conductivity have a major impact on the engine heat transfer characteristics which are manifested by major differences in the combustion chamber wall and bulk gas temperatures. The experimental results presented here therefore confirm that the piston material properties have a first order effect on combustion phasing and consequently the engine-out $\mathrm{HC}$ emissions levels.

The results shown in Figure 13 correspond to a Diesel LTC operating condition and for a SOI timing of $340^{\circ} \mathrm{CA}$. A similar comparison was made between the optical engine equipped with the all-metal (aluminium) piston head and the all-metal engine for a SOI timing variation. Results corresponding to relatively late SOI timings of 350 and $345^{\circ} \mathrm{CA}$ are presented in Figure 14 and Figure 15 respectively. For these SOI timings, the in-cylinder pressure traces reveal

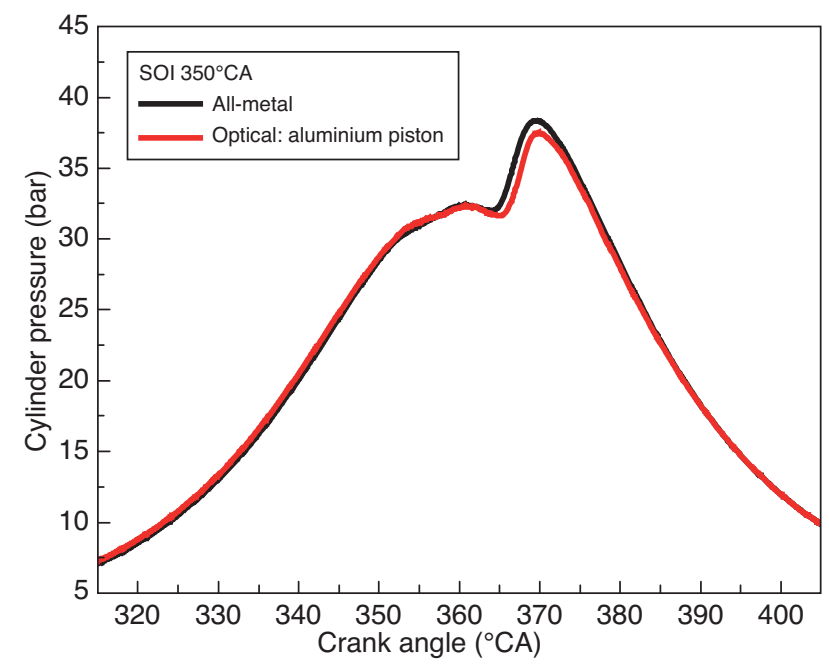

Figure 14

Comparison of fired pressure traces obtained on all-metal engine (red) and optical engine using an all-metal piston (SOI $350^{\circ} \mathrm{CA}$, simulated EGR).

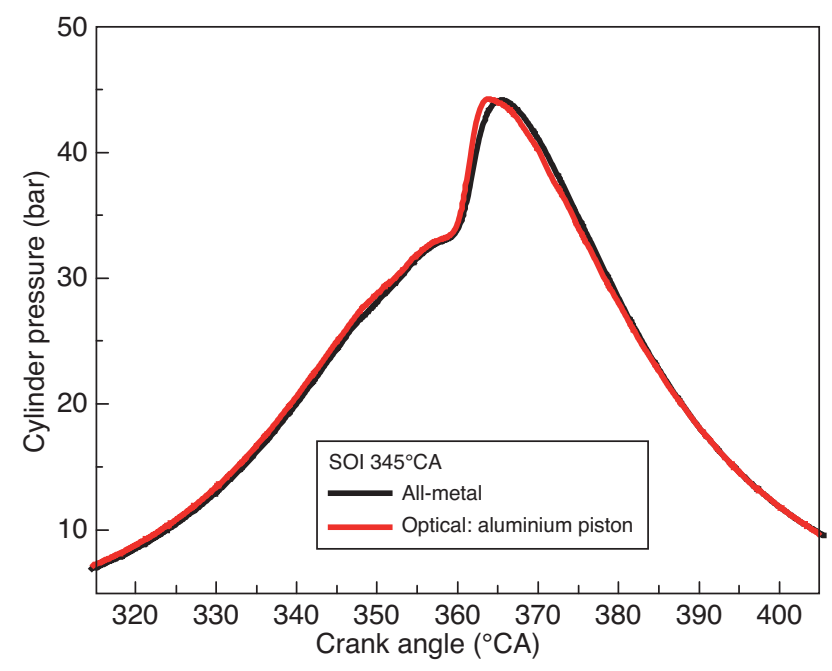

Figure 15

Comparison of fired pressure traces obtained on all-metal engine (red) and optical engine using an all-metal piston (SOI $345^{\circ} \mathrm{CA}$, simulated EGR).

excellent agreement in terms of the combustion phasing between the standard all-metal engine and the optical-access engine equipped with an aluminium piston head.

Data obtained at earlier SOI timings of 300 and $330^{\circ} \mathrm{CA}$ are shown in Figure 16 and Figure 17. At these earlier SOI timing conditions, the results reveal notable differences in combustion phasing between the optical and all-metal engines. For both the 300 and $330^{\circ} \mathrm{CA}$ SOI timings, combustion phasing is clearly advanced on the optical engine compared 


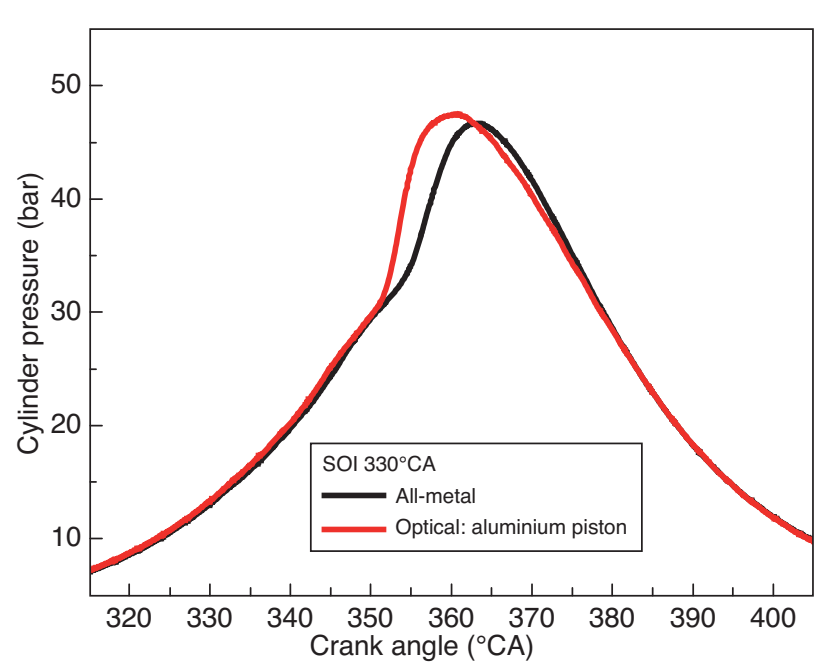

Figure 16

Comparison of fired pressure traces obtained on all-metal engine (red) and optical engine using an all-metal piston (SOI $330^{\circ} \mathrm{CA}$, simulated EGR).

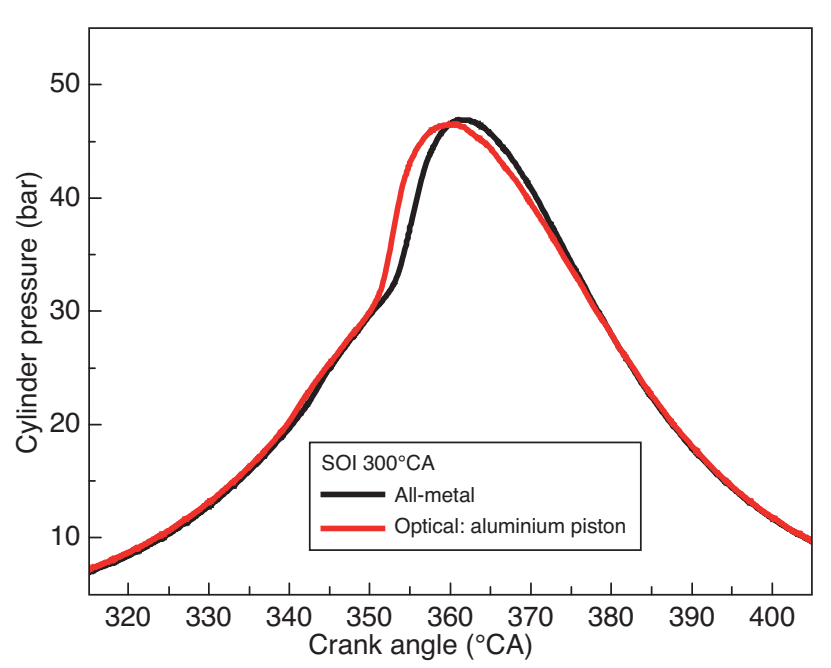

Figure 17

Comparison of fired pressure traces obtained on all-metal engine (red) and optical engine using an all-metal piston (SOI $300^{\circ} \mathrm{CA}$, simulated EGR). to the all-metal engine despite the fact that the optical engine was equipped with a fully representative piston head. It is not yet clear why differences in combustion phasing between the optical and all-metal engines appear to be dependent upon the SOI timing. However, it is important to reiterate that the long auto-ignition delays which correspond to early SOI timings are dominated by chemical kinetics. In contrast, under late SOI timings, auto-ignition is closely coupled to fuel injection which implies that processes such as fuel/air mixing and evaporation are dominant relative to the chemical kinetic timescales. Taking these aspects into account, one possible explication as to why discrepancies in combustion phasing are observed for early SOI timings (i.e. under long ignition delay conditions) is that the in-cylinder temperature distribution between the optical and all-metal engines may differ significantly. Such differences may subsequently affect the chemical kinetic reactions prior to auto-ignition. A second hypothesis is that the differences in combustion phasing under long ignition delay conditions might be related to the EGR gas composition and in particular, the fact that EGR on the optical engine is simulated via pure nitrogen. Indeed, although the approach adopted here was to ensure the correct proportion of nitrogen to air so as to match the in-cylinder oxygen concentration between the two engines, it is clear that real EGR gases contain several other major chemical constituents such as Carbon Monoxide (CO) and Nitrogen Oxide (NO) which are known to have a significant effect on the auto-ignition delay. In summary, the results reveal excellent agreement for relatively late SOI timings whereas notable differences are observed for earlier SOI timings.
The use of relatively late SOI timings (e.g. 345 and $350^{\circ} \mathrm{CA}$ ) means that the injection event is closely coupled to auto-ignition. As a consequence, the fuel evaporation and mixing timescales can be considered dominant relative to the chemical kinetic timescales under "short ignition delay" conditions. In contrast, early SOI timings (e.g. 300 and $330^{\circ} \mathrm{CA}$ ) inherently result in long ignition delays such that the chemical kinetic timescales are dominant relative to the fuel evaporation and mixing timescales. Furthermore, it is well known that the chemical kinetic timescales are highly dependent on both temperature and mixture composition. It is therefore possible that the differences observed in combustion phasing for early SOI timings (i.e. corresponding to long ignition delay conditions) might be due to differences in the in-cylinder temperature distribution and mixture composition in the combustion chamber between the optical and all-metal engines.

The engine-out HC emissions levels measured on both the optical and all-metal engines are presented in Figure 18 for the SOI timing sweep. For relatively late SOI timings (340 to $355^{\circ} \mathrm{CA}$ ), a comparison of the $\mathrm{HC}$ emissions data shows excellent agreement between the two engines. As would be expected, achieving comparable combustion phasing between the all-metal and optical engines results in comparable $\mathrm{HC}$ emissions levels. It should however be reiterated that the optical engine was operated using simulated EGR via pure nitrogen. Therefore, the engine data obtained for these so-called late SOI timings essentially validate the approach adopted here with regards the use of simulated EGR while ensuring that the intake oxygen concentration is matched correctly between the optical and all-metal engines. 


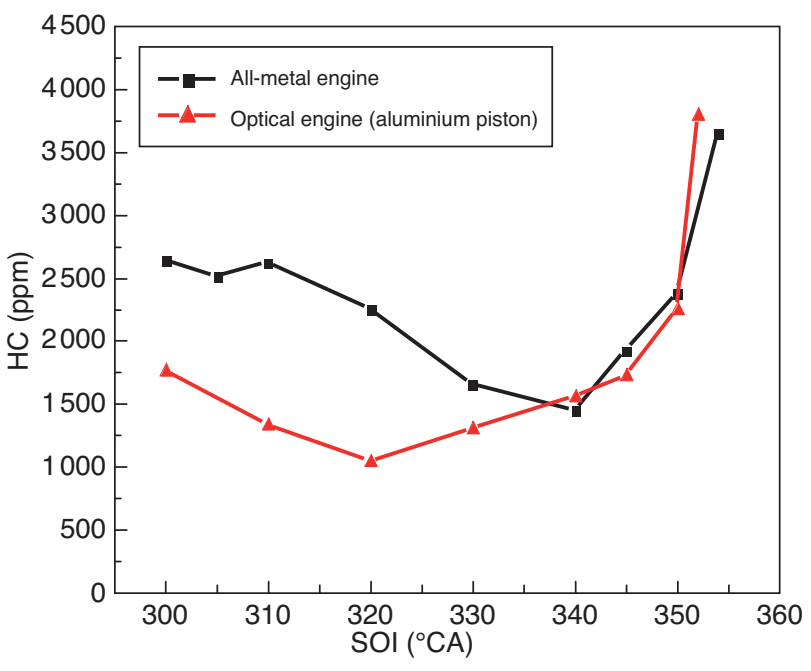

Figure 18

Comparison of $\mathrm{HC}$ emissions as a function of SOI timing for the all-metal engine (using real EGR 45\%) and optical engine (using simulated EGR and aluminium piston), $1500 \mathrm{rpm}$, $\sim 2$ bar IMEP.

As discussed above, noticeable differences in combustion phasing were observed between the two engines when adopting "early" SOI timings (SOI in the range 300 to $330^{\circ} \mathrm{CA}$ ). For these early SOI timings, auto-ignition timing was observed to be systematically over advanced on the optical engine relative to the all-metal engine. One can assume that the shorter ignition delays are indicative of higher combustion temperatures in the case of the optical engine. Indeed this would explain why the measured engine-out HC emissions are significantly lower on the optical engine as revealed in Figure 18 since the higher combustion temperatures encountered on the optical engine will tend to ensure that more of the bulk-gas reactions go to completion. As reported in Reference [8], bulk quenching has been identified as a potentially major source of unburned $\mathrm{HC}$ emissions in Diesel LTC engines. For SOI timings in the range 340 to $355^{\circ} \mathrm{CA}$, similar combustion phasing was well matched between the two engines and Figure 18 reveals that this also correlates with similar levels of engine-out $\mathrm{HC}$ emissions.

Results presented above have shown that piston material properties appear to significantly influence the engine combustion and emissions behaviour as a result of their effects on the engine heat transfer characteristics. In particular, the low thermal conductivity of quartz and titanium in the case of the optical-access piston is believed to generate significantly higher combustion chamber surface temperatures. In an attempt to quantify these differences a non-intrusive diagnostic technique based on Laser-Induced Phosphorescence was used. This technique enabled accurate measurements of piston surface temperature to be performed on both the two-part,

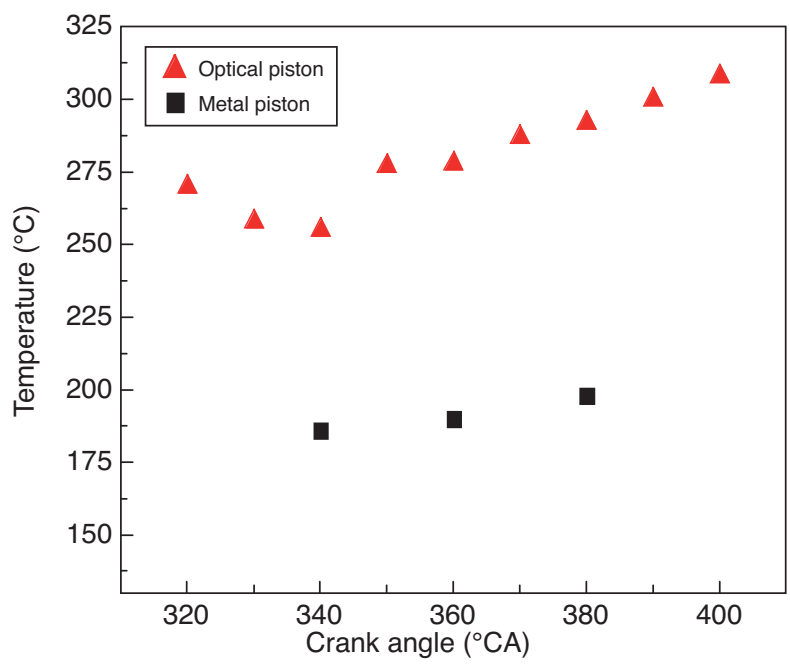

Figure 19

Comparison of piston wall temperature measurements acquired in squish zone for the optical-access (quartz/ titanium) and all-metal (aluminium) pistons, $1200 \mathrm{rpm}, 2$ bar IMEP, SOI $350^{\circ} \mathrm{CA}, 45 \%$ EGR without skip-firing. Ensemble-averaged LIP data over 100 engine cycles at each Crank Angle position.

optical-access piston and subsequently the one-piece, allmetal (aluminium) piston. Results of the Laser-Induced Phosphorescence measurements are shown in Figure 19. The data in Figure 19 reveals the temporal evolution of piston wall temperature between 320 and $400^{\circ} \mathrm{CA}$. The surface temperature measurement location corresponded to the one of the two exhaust valve cut-outs on the top-surface of the piston (i.e. squish zone). As expected, the lower thermal conductivity of quartz and titanium in the case of the optical piston generate significantly higher piston surface temperatures. At this low load ( 2 bar IMEP), LTC operating condition, piston surface temperatures varied in the range 255 to $280^{\circ} \mathrm{C}$ during the compression stroke and exceeded $300^{\circ} \mathrm{C}$ during the early part of the expansion stroke. In contrast however, similar measurements performed on the all-metal piston revealed noticeably lower surface temperatures in the range 185 to $190^{\circ} \mathrm{C}$. Furthermore, the data obtained for the allmetal piston reveals that the measured surface temperature appears to remain approximately constant around TDC while the optical-access piston exhibits significant variations in surface temperature.

\subsection{Geometry and Blow-By Effects}

An attempt has been made to quantify the dynamic (compressive and tensile) loading of the extended piston assembly and in particular how such loading might subsequently result in geometric changes in the combustion chamber volume and 


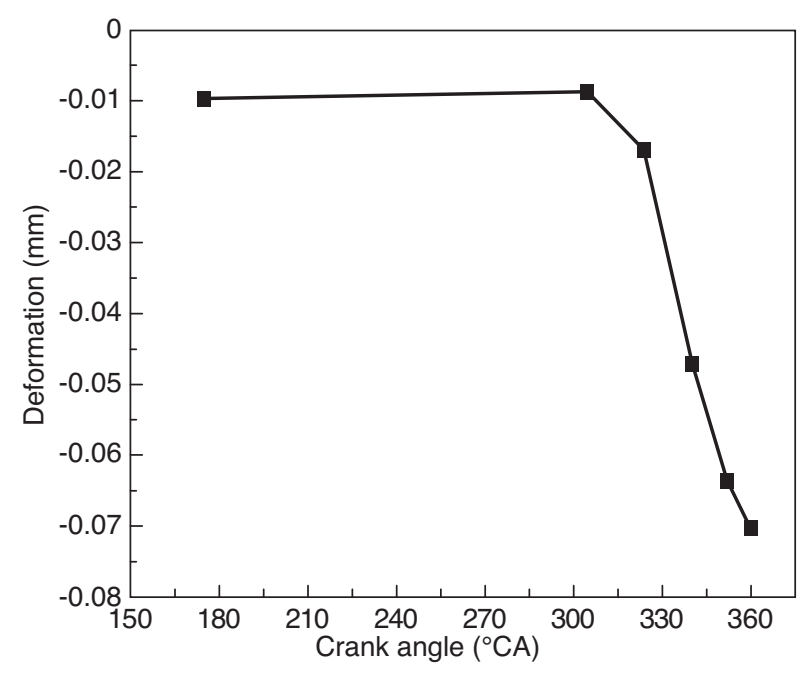

Figure 20

Calculated deformation of extended piston assembly as a function of engine Crank Angle under motored conditions, CR 14:1, $1200 \mathrm{rpm}$.

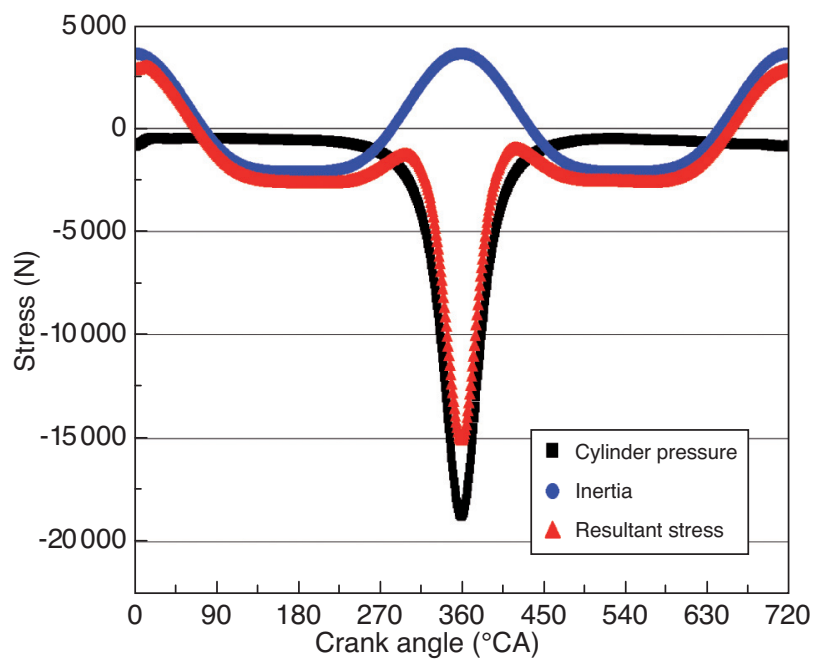

Figure 21

Calculated stresses showing inertial and compressive components (in-cylinder pressure) and the resultant stress as a function of engine Crank Angle, CR 14:1, $1200 \mathrm{rpm}$. therefore the engine Compression Ratio. Finite Element Analysis (FEA) calculations were performed using commercially available software (CATIA) to evaluate the effects of loading on the extended piston assembly used on the optical engine (Fig. 20 and Fig. 21). A motored pressure trace provided the initial conditions for the design calculations and provided the range of pressures exerted on the extended piston as a function of engine Crank Angle. Data obtained via the FEA analysis revealed the stress induced in the axis of symmetry of the extended piston and the resulting deformation (i.e. either elongation or compression of the piston assembly). The change in total crevice volume associated with the compressive or tensile loading could then be estimated.

Data presented in Figure 20 reveals the deformation (in $\mathrm{mm}$ ) of the extended piston assembly as a function of engine Crank Angle. For the sign convention adopted here a negative deformation implies compression while positive values of deformation imply tensile loading. The effects of inertia have been taken into account in the calculations performed within this study. Inertial forces can potentially compensate to a certain extent against the compressive loading which the extended piston is subjected to as a result of high cylinder pressures. Since inertial effects were taken into account, the results shown in Figure 19 apply to the optical engine operating at an engine speed of $1200 \mathrm{rpm}$. The data reveals that the deformation remains approximately constant between BDC $\left(180^{\circ} \mathrm{CA}\right)$ and $310^{\circ} \mathrm{CA}$. During the compression stroke, the piston assembly undergoes compressive strain due to the increasing cylinder pressure. The compressive loading induces a maximum of approximately $0.07 \mathrm{~mm}$ at TDC. The resulting change in combustion chamber crevice volume is estimated to be $400 \mathrm{~mm}^{3}$. This corresponds to a change in engine Compression Ratio of 0.13 .

The offset of $-0.1 \mathrm{~mm}$ in Figure 19 between 175 and $300^{\circ} \mathrm{CA}$ might not initially appear intuitive. Clearly, the compressive forces which might be induced by in-cylinder pressure are negligible since the in-cylinder pressure is approximately 1 bar (i.e. atmospheric pressure) during this part of the engine cycle and so the offset cannot be attributed to compression of the extended piston. In fact, the inertial forces due to the weight of the extended piston assembly as it accelerates from Bottom Dead Centre (BDC) towards TDC during the compression stroke will induce a certain degree of compressive strain. This results in the $0.1 \mathrm{~mm}$ deformation observed between $175^{\circ} \mathrm{CA}$ and $305^{\circ} \mathrm{CA}$ and increases thereafter.

Calculations of the extended piston deformation were also performed for a wide range of TDC pressures and for three engine speeds of 1200,2000 and $3000 \mathrm{rpm}$. The results presented in Figure 22 reveal that at $1200 \mathrm{rpm}$, the extended piston assembly undergoes compressive strain for TDC pressures exceeding approximately $10 \mathrm{bar}$. At higher engine speeds, the higher inertial forces induce greater tensile loading of the piston assembly. As a result, the threshold TDC pressure which leads to negative deformation (i.e. compression) is significantly higher. At $3000 \mathrm{rpm}$, compressive loading would be expected for TDC pressures of at least 35 bar. As expected, the extended piston deformation varies linearly as a function of TDC pressure. Engine speeds of $1200 \mathrm{rpm}$ and maximum cylinder pressures in the range of 80 to 90 bar are 


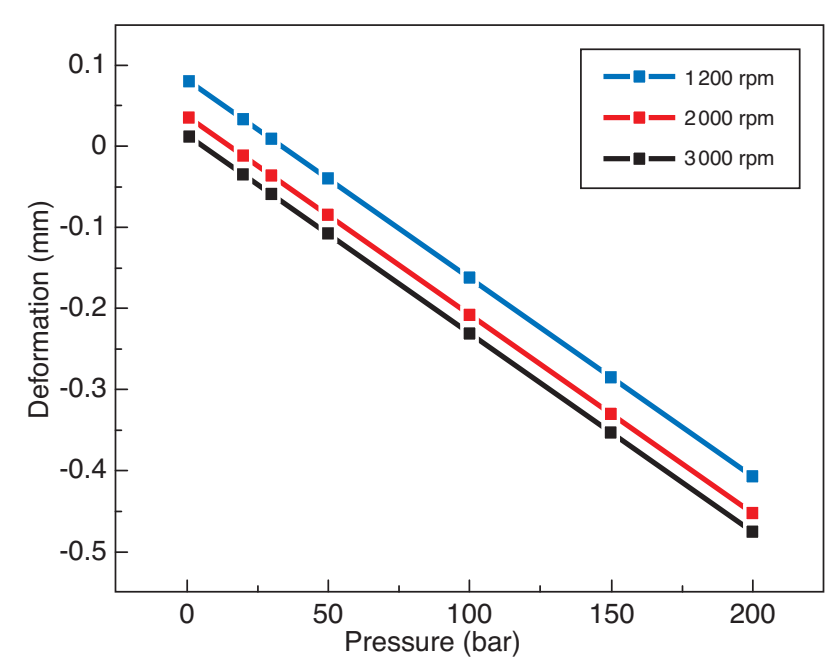

Figure 22

Calculated deformation of extended piston assembly as a function of TDC pressure for engine speeds of 1200,2000 and $3000 \mathrm{rpm}$.

fairly typical for optical engine studies such as the one used in this investigation.

At these conditions, results from Figure 22 reveal that the extended piston would be compressed by approximately $0.2 \mathrm{~mm}$, resulting in an increase of the combustion chamber crevice volume of approximately $1300 \mathrm{~mm}^{3}$. This amounts to a reduction in the geometric Compression Ratio of 0.44 . For the optical engine used in this study, the nominal Compression Ratio of 14:1 would therefore decrease to 13.56 due to piston compression. In fact it should be noted that the Compression Ratio of the optical engine used in the current study was increased to $14.5: 1$ in order to match the motored pressure trace (Fig. 8). This Compression Ratio was maintained for all subsequent experiments performed on the optical engine and reported in this paper. Results obtained from the design calculations thus appear to indicate that the $\sim 0.5$ increase in Compression Ratio which is required on the optical engine in order to achieve comparable combustion phasing with the all-metal engine corresponds primarily to a compensation of the compressive loading effects rather than effects which might be related to engine blow-by. Furthermore, it would also appear that thermal expansion effects are not significant on this particular engine. This is perhaps not surprising since the engine block and supports which bridge the engine base with the cylinder head are all manufactured from steel while the extended piston is also manufactured from steel. Since these major engine components are manufactured from the same material, the degree of thermal expansion of these engine parts can be assumed to be similar. Any geometrical differences which therefore might arise as a result of differences in thermal expansion (due to differences in material thermal expansion) would be assumed to be negligible.

\subsection{Methods for Combustion Phasing Matching Between Optical and All-Metal Engines}

\subsubsection{Skip-Firing Strategies}

As discussed earlier, the low conductivity of materials such as quartz and titanium which are commonly used in optical engines leads to significantly higher combustion chamber surface temperatures. This makes it difficult to attain comparable combustion and emissions behaviour between optical and all-metal engines. Skip-firing strategies can be employed as a means to adjust combustion phasing since the motored (non-fired) cycles allow sufficient cooling of the combustion chamber surfaces. As shown in Figure 23, the use of skip-firing strategies has a significant influence on the combustion phasing. The data presented reveal that adopting a $1 / 5$ skip-firing strategy with the optical piston is sufficient in order to obtain similar combustion phasing to the aluminium (all-metal) piston. For this particular engine and for these operating conditions, increasing the number of non-fired cycles and adopting a 1/10 skip-firing strategy does not appear to have any further effect on the combustion phasing.

Clearly, other skip-firing strategies can be adopted. For example, 10 successive fired cycles followed by 90 motored cycles is a strategy reported in Reference [1]. The data acquisition is then performed on the 10th fired cycle. This 10/100 skip-firing strategy is particularly important when burned gas

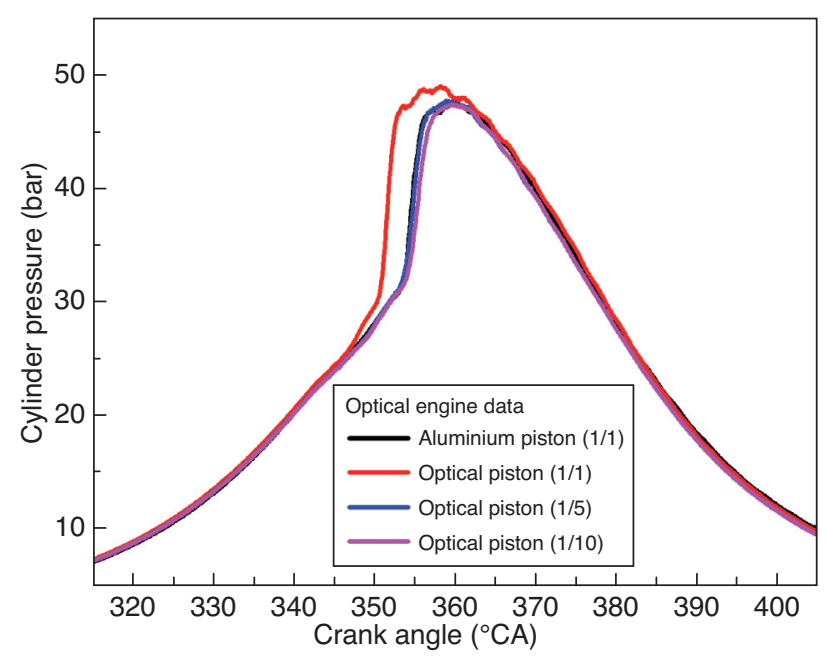

Figure 23

Comparison of fired pressure traces acquired on optical engine showing effect of skip-firing strategy on combustion phasing relative to metal engine data, $1200 \mathrm{rpm}, 2$ bar IMEP, $P_{i n j} 1000$ bar, standard Diesel fuel. 
residual gases need to be taken into account which is particularly the case in Spark Ignition (SI) engines. However, the use of such strategies means that data acquisition time will be significantly increased.

\subsubsection{Adjusting Engine Coolant and/or Intake Temperature}

Skip-firing strategies should generally be employed as a first step in order to achieve matching combustion phasing between optical and all-metal engines. However, further efforts may be required in order to obtain a very accurate agreement. Small variations of the engine coolant and/or intake charge temperature could be made for example. Results presented in Figure 24 show a comparison of heat release data obtained on the optical engine with an all-metal (aluminium) and optical piston. The data obtained using the all-metal piston was obtained without skip-firing while in the case of the optical piston data, $1 / 5$ skip-firing was employed. The results reveal that for this operating condition and at the nominal coolant temperature of $85^{\circ} \mathrm{C}$, the skip-firing strategy alone is not sufficient to attain comparable combustion phasing between the optical and all-metal configurations. Decreasing the coolant temperature to $60^{\circ} \mathrm{C}$ in the case of the optical piston provided the necessary level of combustion retard in order to achieve comparable combustion phasing with the all-metal configuration. Alternatively, the intake temperature can be adjusted if necessary in order to match combustion phasing between the two engines. It should be noted however that parameters such as the intake mass flow

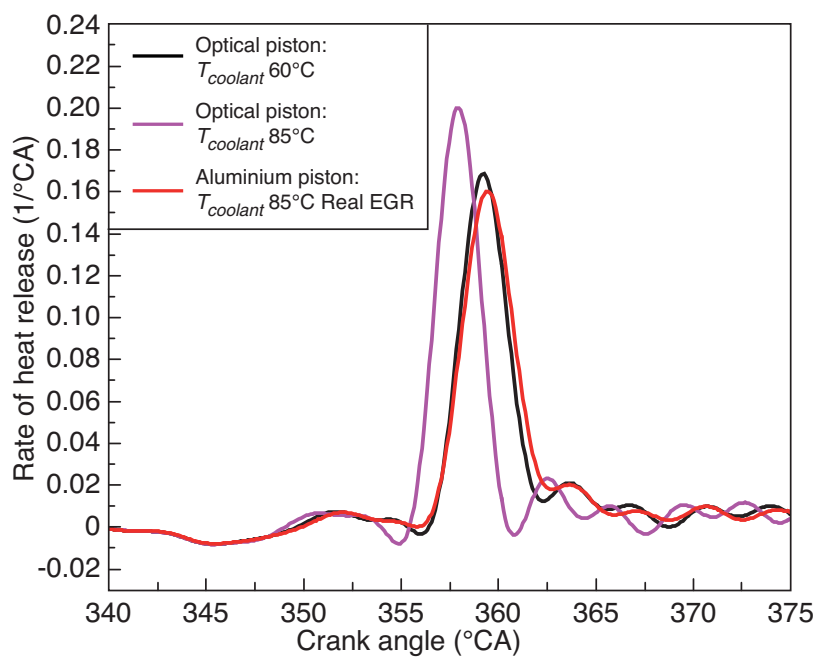

Figure 24

Comparison of heat release rates obtained on optical engine with all-metal and optical pistons showing effect of adjusting engine coolant temperature, $1200 \mathrm{rpm}, \sim 2$ bar IMEP. and intake pressure should be identical on both the optical and all-metal engines.

\subsubsection{Representative Fuels for Optical Engine Studies}

Single component, "pure" (i.e. non-fluorescing) fuels are often used on optical engines due to laser diagnostic constraints. Commercial gasoline and Diesel fuels contain aromatic and naphthenic compounds (considered fuel "impurities" from a laser diagnostic viewpoint) which result in significant LIF emission upon ultraviolet (UV) laser excitation. For gasoline engine studies, fuels such as isooctane and Primary Reference Fuels (PRF) which are mixtures of isooctane and $n$-heptane are frequently used while on Diesel engines, decane and dodecane fuels are more commonly employed $[3,4]$ since their Boiling Points are reasonably close to the lower Boiling Points of standard Diesel fuel (dodecane: $T_{b}=$ $216^{\circ} \mathrm{C}$, decane: $T_{b}=174^{\circ} \mathrm{C}$ ). However decane and dodecane fuels have significantly higher Cetane Numbers (dodecane: $\mathrm{CN} \sim 71$, decane: $\mathrm{CN} \sim 76$ ) compared to standard Diesel fuel $(\mathrm{CN} \sim 52)$ which will inevitably result in shorter auto-ignition delays. Therefore, when laser-based diagnostic techniques are employed on optical engines in order to complement allmetal engine data, particular attention should be given to the fuel auto-ignition and spectroscopic properties.

All optical engine data presented above was obtained using standard Diesel fuel however since many laser diagnostic techniques applied in optical engines require that the fuel be non-fluorescent, standard Diesel fuel cannot be used. An alternative "pure" (or non-fluorescing) fuel must be identified in order to satisfy the spectroscopic requirements but at the same time ensuring that the fuel Cetane Number is comparable to that of standard Diesel fuel. A fuel blend containing Diesel fuel derived from a Fischer Tropsch (FT) process and an isoparaffin solvent (Isane IP 185) was formulated. Previous studies reported in Reference [17] using FT fuel revealed that this fuel did not fluoresce following laser excitation at $355 \mathrm{~nm}$, probably due to the low concentration of aromatic and naphthenic compounds. Laser excitation at $266 \mathrm{~nm}$ of this fuel did nonetheless result in noticeable LIF emission. However, the Cetane Number of the FT fuel $(\mathrm{CN} 76)$ was significantly higher than that of standard Diesel fuel (Tab. 3).

A low Cetane Number $(\mathrm{CN}$ 33) isoparaffin solvent (Isane IP 185) was blended with the FT fuel in order to obtain a Cetane Number comparable with standard Diesel fuel. Isane IP 185 contains neither aromatic compounds, nor benzene and was therefore chosen since it was not be expected to fluoresce. Subsequent LIF measurements indeed confirmed that the fuel blend did not exhibit detectable fluorescence emission following laser excitation at $355 \mathrm{~nm}$. Having verified the fuel blend spectroscopic characteristics, subsequent tests were performed in a Cooperative Fuel Research (CFR) engine to measure Cetane Number. A blend of 55\% (by 
TABLE 3

Measured properties of standard Diesel, Fischer Tropsch and Isane IP 185 used in this study

\begin{tabular}{l|c|c|c}
\hline & $\begin{array}{c}\text { Standard } \\
\text { Diesel fuel }\end{array}$ & $\begin{array}{c}\text { Fischer } \\
\text { Tropsch }\end{array}$ & $\begin{array}{c}\text { Isane } \\
\text { IP 185 }\end{array}$ \\
\hline Cetane Number & $\sim 52$ & 76 & 33 \\
\hline Density $\left(\mathrm{kg} / \mathrm{m}^{3}\right)$ & 842 & 768 & 765 \\
\hline Boiling range $\left({ }^{\circ} \mathrm{C}\right)$ & $201-364$ & $206-301$ & $187-206$ \\
\hline Aromatic content $(\%)$ & 27.1 & 0.3 & $<0.001$ \\
\hline Sulphur content $(\mathrm{ppm})$ & 35 & $<10$ & $<1$ \\
\hline Viscosity at $40^{\circ} \mathrm{C}\left(\mathrm{mm}{ }^{2} / \mathrm{s}\right)$ & 3.7 & 2.1 & 1.3 \\
\hline Paraffin content $(\%)$ & 39.1 & 95.9 & 100 \\
\hline
\end{tabular}
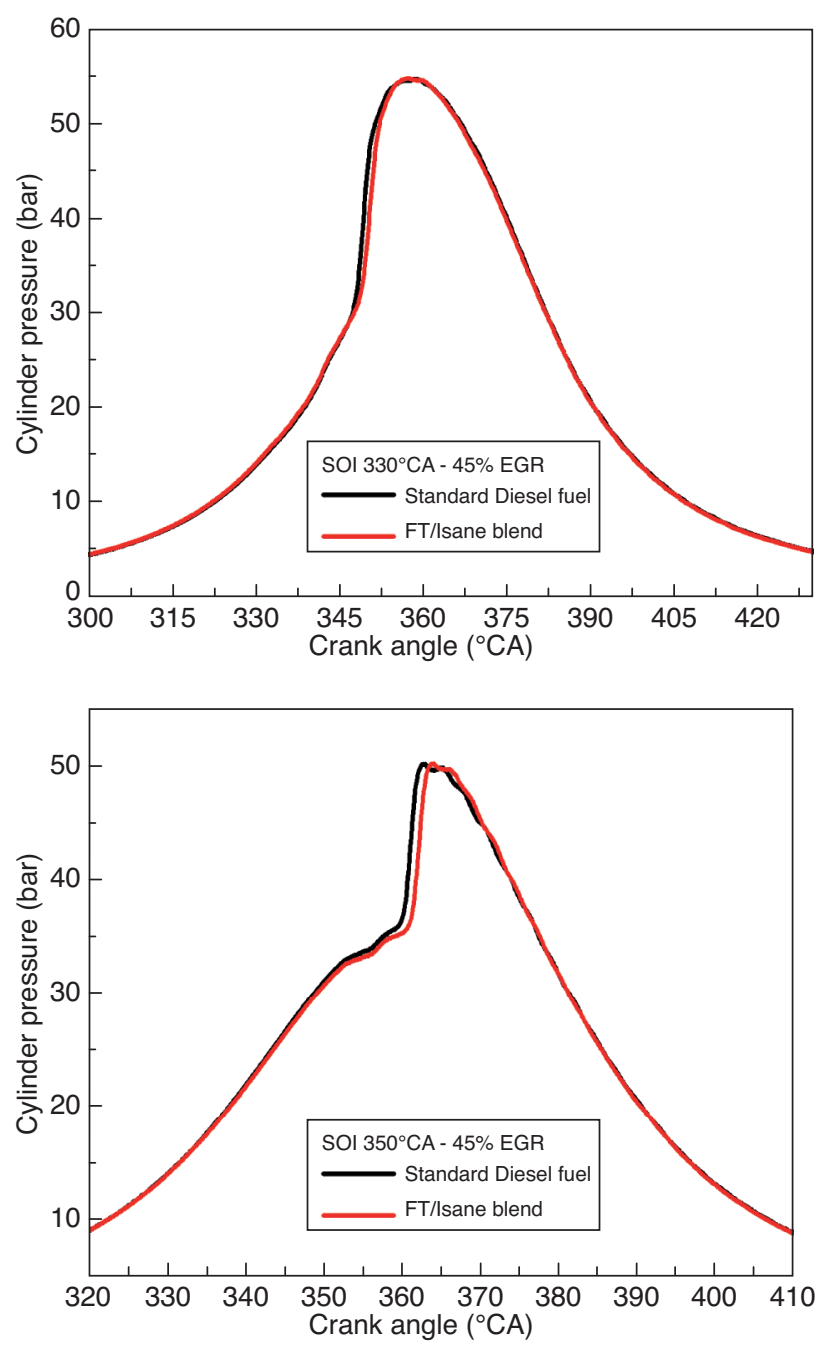

Figure 25

Comparison of measured in-cylinder pressure traces obtained using standard Diesel fuel and Fischer Tropsch/Isane fuel blend for SOI at $330^{\circ} \mathrm{CA}$ (upper graph) and $350^{\circ} \mathrm{CA}$ (lower graph) under LTC conditions, optical engine tests, $1200 \mathrm{rpm}$, 2 bar IMEP.

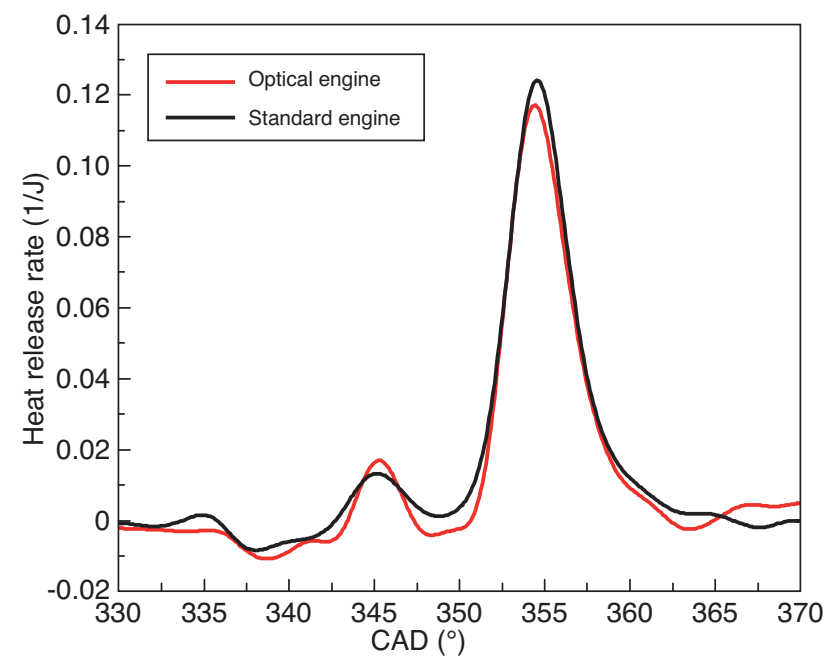

Figure 26

Comparison of heat release rates obtained on optical engine (with Fischer Tropsch/Isane fuel blend) and standard allmetal engine (with standard Diesel fuel) for an early injection strategy (SOI $336^{\circ} \mathrm{CA}$ ) corresponding to partially premixed, LTC conditions, $1200 \mathrm{rpm}, 2$ bar IMEP.

weight) FT fuel and of $45 \%$ Isane IP 185 was found to have a Cetane Number of 52, comparable to the Diesel fuel used in this study. Finally, in order to further validate the FT/Isane fuel blend, a back-to-back comparison of the fuel blend with standard Diesel fuel was performed on the optical engine. Measured in-cylinder pressure traces acquired at two different SOI timings (SOI at 330 and $350^{\circ} \mathrm{CA}$ ) are shown in Figure 25 and reveal excellent agreement between the two fuels confirming that the FT/Isane fuel blend was representative of standard Diesel fuel in terms of its auto-ignition characteristics and was therefore used as a surrogate fuel to represent standard Diesel fuel on all experiments performed on the optical engine.

The FT/Isane fuel blend reported here has been used on the IFPEN optical Diesel engine to study the fuel and distribution and auto-ignition characteristics using advanced injection strategies (injection rate shaping and double injections) under Diesel LTC operating conditions. As reported in Reference [17], excellent agreement was achieved in terms of combustion phasing matching between the optical engine and a standard, single cylinder all-metal engine for advanced single injection and for closely-spaced double injection strategies. A comparison of heat release data acquired on the optical and all-metal engines is shown in Figure 26 using the FT/Isane fuel blend and standard Diesel fuel respectively. The data was obtained for an early SOI timing $\left(336^{\circ} \mathrm{CA}\right)$ corresponding to partially premixed (Diesel LTC) conditions and reveal that very satisfactory agreement of both the cool-flame and main heat release was achieved. 


\section{CONCLUSIONS}

The use of optical engines and laser-based diagnostic techniques as a means of gaining a detailed insight and an improved understanding of in-cylinder mixing, combustion and emissions phenomena is well known. However, the ability to ensure fully representative combustion and emissions behaviour of optical engines increases the value of optical engine data highlighting the importance of using such engines as research tools for the further development of innovative, low emission combustion concepts.

A detailed comparison of the combustion and emissions performance of a single-cylinder, optical-access and a standard all-metal engine of identical geometry has been performed under Diesel LTC operating conditions. The principal differences between the two engines were identified and the effects of these differences on mixing, combustion and emissions formation have been discussed.

Results have shown the significant effect of material properties on the combustion chamber wall heat transfer characteristics for the optical and all-metal engines. In particular, the low thermal conductivity materials typically used on optical engines lead to higher wall and bulk gas temperatures which have a major effect on combustion phasing and engine-out emissions. Non-intrusive piston surface temperature measurements were performed using the Laser-Induced Phosphorescence technique. Results acquired at a $1200 \mathrm{rpm}$ and 2 bar IMEP operating condition revealed surface temperatures near to TDC in excess of $300^{\circ} \mathrm{C}$ for the optical-access piston compared with $\sim 190^{\circ} \mathrm{C}$ for the all-metal piston.

The use of skip-firing strategies on the optical engine has been shown to have a first order effect on combustion phasing and is necessary to match both combustion phasing and engine-out emissions levels. A comparison was also made between simulated EGR (via pure nitrogen) and real EGR over a wide range of injection timings. Results revealed the importance of matching the correct intake oxygen concentration when using simulated EGR. For injection timings in the range 330 to $350^{\circ} \mathrm{CA}$, a comparison of simulated EGR versus real EGR revealed excellent agreement in terms of combustion phasing and engine-out $\mathrm{HC}$ emissions.

The effects of dynamic loading of the extended piston assembly were also investigated. Estimates of the deformation of the extended piston were obtained over a range of simulated in-cylinder pressures. These results revealed that compression of the optical engine piston assembly will have a notable effect on the combustion chamber crevice volume and therefore the effective Compression Ratio. Furthermore, the design calculations and experimental data tend to indicate that a 0.5 increase in Compression Ratio was required on this particular optical engine as a means of achieving combustion phasing comparable with the all-metal engine. More importantly, it was shown that the adjustment in Compression Ratio is primarily due to the need to compensate for the com- pressive loading effects of the extended piston rather than for engine blow-by and/or thermal expansion effects.

Finally, in an effort to improve the operating range (load and speed) of the future generation of optical engines, key challenges which need to be considered concern technical solutions which will allow better control/regulation of combustion chamber wall temperature and the deformation of the extended piston assembly due to dynamic loading effects. These aspects are not only important for ensuring adequate robustness of optical engines but also ensuring their representativity compared to standard all-metal engines.

\section{ACKNOWLEDGMENTS}

This research was partly conducted within the framework of a research program funded by the Groupement Scientifique Moteurs (IFP Energies nouvelles, PSA and Renault) for which financial support is gratefully acknowledged.

\section{REFERENCES}

1 Steeper R.R., Stevens E.J. (2000) Characterization of Combustion, Piston Temperatures, Fuel Sprays and Fuel-Air Mixing in a DISI Optical Engine, SAE paper 2000-01-2900.

2 Koyanagi K., Öing H., Renner G., Maly R. (1999) Optimizing Common Rail Injection by Optical Diagnostics in a Transparent Production Type Diesel Engine, SAE paper 1999-01-3646.

3 Hochgreb S. (2001) Fuel Distribution and Combustion Characteristics in a Direct-Injection, Spark-Ignited (DISI) Engine Under Stratified Operation, SAE paper 2001-01-3645.

4 Kashdan J.T., Docquier N., Bruneaux G. (2004) Mixture Preparation and Combustion via LIEF and LIF of Combustion Radicals in a Direct-Injection, HCCI Diesel Engine, SAE Transactions, Int. J. Fuels Lubricants, SP-1896, 2004, SAE paper 2004-01-2945.

5 Kashdan J.T., Papagni J.-F. (2005) LIF Imaging of Auto-Ignition and Combustion in a Direct-Injection, Diesel-Fuelled HCCI Engine, SAE paper 2005-01-3739.

6 Colban W.F., Kim D., Miles P.C., Oh S., Opat R., Krieger R., Foster D., Durrett R.P., Manuel A., Gonzalez D. (2008) A Detailed Comparison of Emissions and Combustion Performance between Optical and Metal Single-Cylinder Diesel Engines at Low Temperature Combustion Conditions, SAE paper 2008-01-1066.

7 Aronsson U., Chartier C., Horn U., Andersson O., Johansson B., Egnell R. (2008) Heat Release Comparison Between Optical and All-Metal HSDI Diesel Engines, SAE paper 2008-01-1062.

8 Kashdan J.T., Mendez S., Bruneaux G. (2007) On the Origin of Unburned Hydrocarbon Emissions in a Wall-Guided, Low NOx Diesel Combustion System, SAE Transactions, J. Fuels Lubricants 4, 116, 234-257, SAE paper 2007-01-1836.

9 Kashdan J.T., Bruneaux G. (2011) Laser-Induced Phosphorescence Measurements of Combustion Chamber Surface Temperature on a Single-Cylinder Diesel Engine, SAE paper 2011-01-2049, JSAE/SAE 2011 Powertrains, Fuels and Lubricants Conference, Kyoto, 2011.

10 Allison S.W., Gillies G.T. (1997) Remote Thermometry With Thermographic Phosphors: Instrumentation and Applications, Rev. Sci.Instrum. 68, 7, 2615. 
11 Armfield J.S., Graves R.L., Beshears D.L., Cates M.R., Smith T.V., Allison S.W. (1997) Phosphor Thermometry for Internal Combustion Engines, SAE paper 971642.

12 Omrane A., Juhlin G., Aldén M., Josefsson G., Engström J., Benham T. (2004) Demonstration of Two-Dimensional Temperature Characterization of Valves and Transparent Piston in a GDI Optical Engine, SAE paper 2004-01-0609.

13 Husberg T., Gjirja S., Denbratt I., Omrane A., Aldén M., Engström J. (2005) Piston Temperature Measurement by Use of Thermographic Phosphors and Thermocouples in a Heavy-Duty Diesel Engine Run Under Partly Premixed Conditions, SAE paper 2005-01-1646.

14 Allison S.W., Beshears D.L., Benic T., Hollerman W.A., Boudreaux P. (2001) Development of Temperature-Sensitive Paints for High-Temperature Aeropropulsion Applications, AIAA paper 2001-3528, pp. 1-7.

15 Tobin K.W., Allison S.W., Cates M.R., Capps G.J., Beshears D.L., Cyr M., Noel B.W. (1990) High-Temperature Phosphor Thermometry of Rotating Turbine Blades, AIAA J.28, 8 .
16 Ladommatos N., Xiao Z., Zhao H. (2005) The Effect of Piston Bowl Temperature on Diesel Exhaust Emissions, Proc. IMechE. Part D: J. Automobile Engineering 219, 371-388.

17 Maly R.R., Schaefer V., Hass H., Cahill G.F., Rouveirolles P., Röj A., Wegener R., Montagne X., Di Pancrazio A., Kashdan J.T. (2007) Optimum Diesel Fuel for Future Clean Diesel Engines, SAE Transactions J. Fuels Lubricants 4, 116, 28-47, SAE paper 2007-01-0035.

18 Kashdan J.T., Anselmi P., Walter B. (2009) Advanced Injection Strategies for Controlling Low-Temperature Diesel Combustion \& Emissions, SAE Transactions, Int. J. Engines 2, 1, 1835-1872, SAE paper 2009-01-1962.

19 Hwang W., Dec J.E., Sjöberg M. (2008) Spectroscopic and Chemical-Kinetic Analysis of the Phases of HCCI Autoignition and Combustion for Single- and Two-Stage Ignition Fuels, Combust. Flame 154, 387-409.

Final manuscript received in March 2011 Published online in November 2011 or distributed for profit or commercial advantage and that copies bear this notice and the full citation on the first page. Copyrights for components of this work owned by others than IFP Energies nouvelles must be honored. Abstracting with credit is permitted. To copy otherwise, to republish, to post on servers, or to redistribute to lists, requires prior specific permission and/or a fee: Request permission from Information Mission, IFP Energies nouvelles, fax. +331475270 96, or revueogst@ifpen.fr. 